\title{
SUBSTRATE DEPENDENT REGULATION OF THE HUMAN EQUILIBRATIVE NUCLEOSIDE TRANSPORTER 1 (hENT1) IN HEK293 CELLS
}

by

Maliha Zafar, Honours BSc York University 2013

\author{
A thesis presented to Ryerson University \\ in partial fulfillment of the \\ requirements for the degree of \\ Master of Science \\ in the Program of \\ Molecular Science
}

Toronto, Ontario, Canada, 2015

CMaliha Zafar 2015 


\section{AUTHOR'S DECLARATION FOR EELCTRONIC SUBMISSION OF A THESIS}

I hereby declare that I am the sole author of this thesis. This is a true copy of the thesis, including any required final revisions, as accepted by my examiners.

I authorize Ryerson University to lend this thesis to other institutions or individuals for the purpose of scholarly research.

I further authorize Ryerson University to reproduce this thesis by photocopying or by other means, in total or in part, at the request of other institutions or individuals for the purpose of scholarly research.

I understand that my thesis may be made electronically available to the public. 


\title{
Abstract
}

\section{SUBSTRATE DEPENDENT REGULATION OF THE HUMAN EQUILIBRATIVE NUCLEOSIDE TRANSPORTER 1 (hENT1) IN HEK293 CELLS}

\author{
Maliha Zafar \\ Master of Science, Molecular Science, Ryerson University, 2015
}

Nucleosides and nucleoside analog drugs enter cells through nucleoside transporters, such as the human equilibrative nucleoside transporter 1 (hENT1). The regulation of nucleoside transporters is poorly understood. In this study, through fluorescence-activated cell sorting (FACS) analyses, confocal microscopy and radio-ligand binding assays, I show a decrease in hENT1 abundance at the plasma membrane (PM) in HEK cells treated in the presence of a bolus amount of cytidine $(40 \mu \mathrm{M})$ for 6 hours. Kinetic and transport assays indicate that the remaining hENT1 population at the PM has a higher $\mathrm{V}_{\max }$ and $\mathrm{K}_{\mathrm{m}}$ but there is no change in overall substrate uptake compared to untreated cells. I also show that cytidine pre-treatment leads to an increased cytotoxicity from gemcitabine (a nucleoside analog drug). These are the first data that show direct substrate dependent regulation of a nucleoside transporter by a mechanism that may involve increased recycling/internalization of the transporter. 


\section{Acknowledgements}

I would first like to thank my supervisor, Dr Imogen Coe. Thank you for your guidance and reassurance throughout my time as your student. I am thankful to you for helping me develop my scientific writing and for teaching me how to ask the right questions as a scientist.

The Coe lab, I thank you all for the endless support I received from you. I will miss you all.

Zlatina: thanks for all your wisdom and making me see the brighter side of things. It was a big relief to know that I had someone to fall back on when I made mistakes or was lost.

Natalia, Alex, Maria-Cristina, and Julia: thank you all for making the lab a fun, welcoming place. It was always nice to talk to you all and realize that we're all in the same boat. Thanks also for helping me with my scientific questions and sharing your "tips" and "tricks" in the lab.

I also want to thank Chris Spring from St. Michael's Hospital Research Core Facilities for making my flow cytometry analyses a fun experience.

A special thanks to my committee members, Dr Costin Antonescu and Dr Raffi Karshafian, for always helping me think deeply and analyze my work with a different perspective.

Finally, a big thank you to my family and friends. Thanks for your encouragement, for listening to my "problems" and always cheering me up. 


\section{Table of Contents}

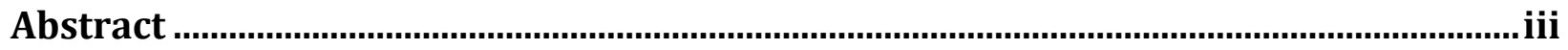

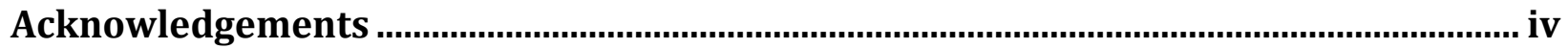

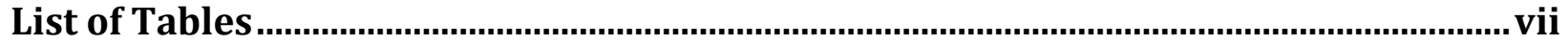

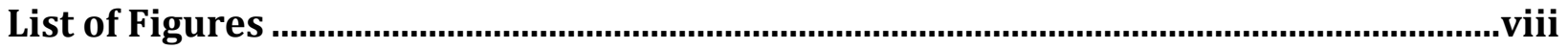

List of abbreviations .................................................................................................. ix

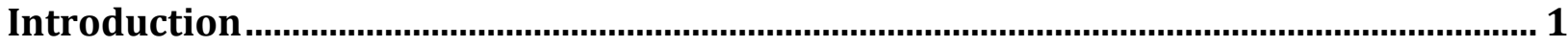

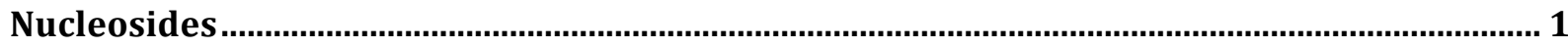

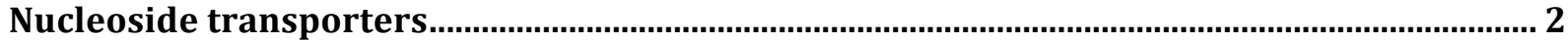

CNTs

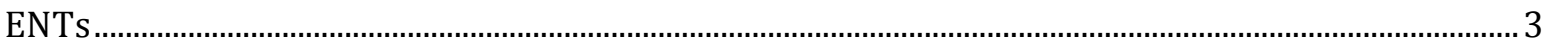

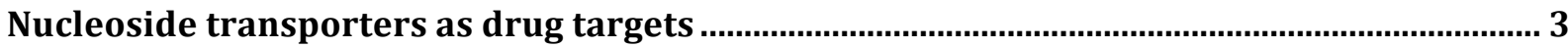

ENT1

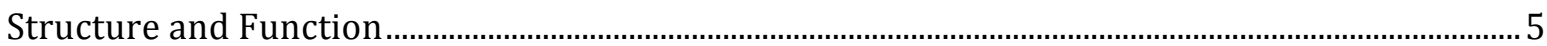

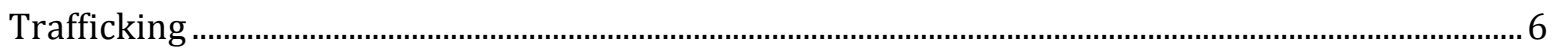

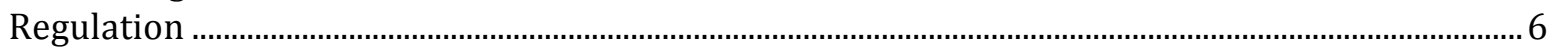

Thesis rationale and hypothesis ................................................................................... 11

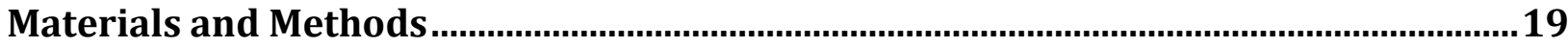

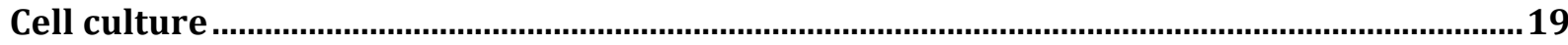

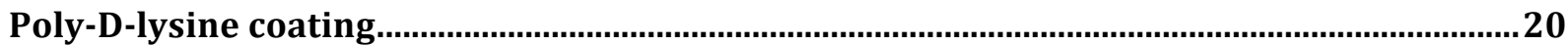

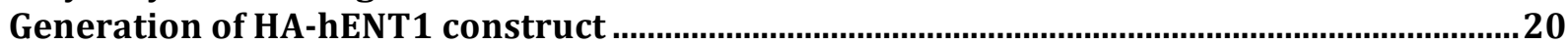

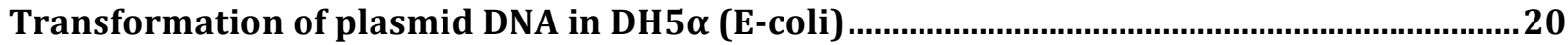

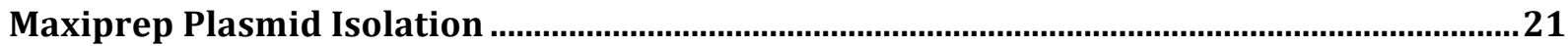

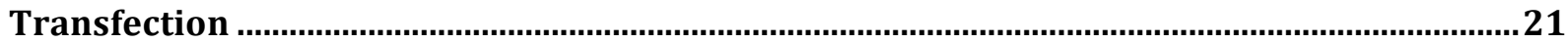

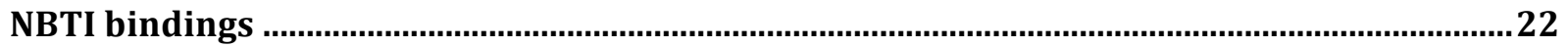

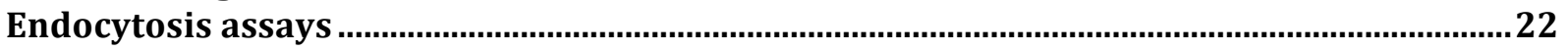

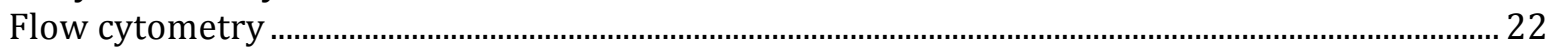

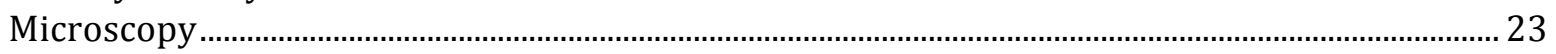

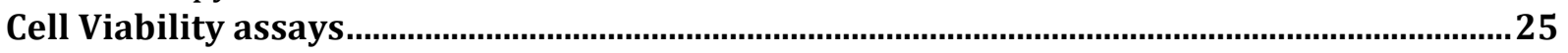

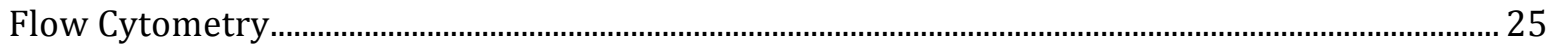

MTT (3-(4, 5-dimethylthiazolyl-2)-2, 5-diphenyltetrazolium bromide) assay................................ 26

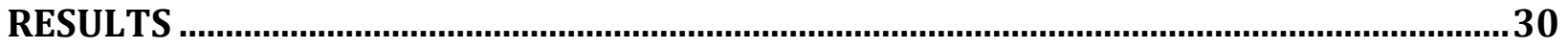

Cytidine exposure leads to a decrease in surface fluorescence from HA-hENT1 1...................30

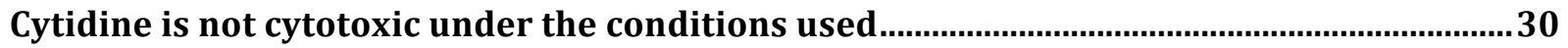

Cytidine exposure leads to the formation of intracellular punctate structures .....................30

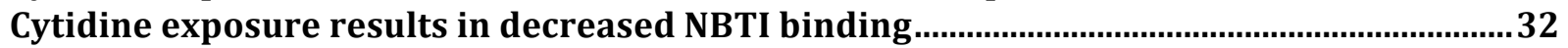

hENT1-dependent substrate uptake does not decrease with prior exposure to cytidine...33

Cytidine exposure leads to altered transport kinetics of hENT1 ...............................................34

Cytidine pre-treatment results in an increased cytotoxicity from gemcitabine......................35

Discussion...................................................................................................................................45

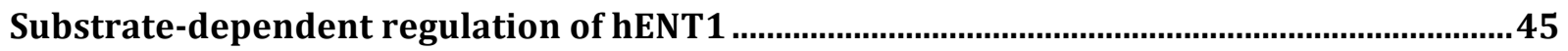

The effect of cytidine pre-treatment on gemcitabine efficacy.................................................51

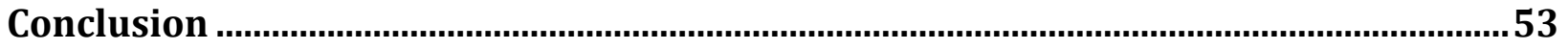




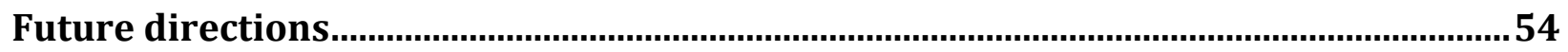

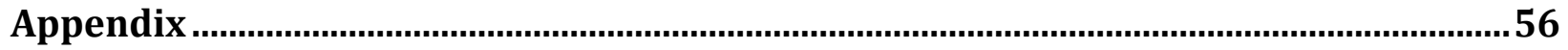

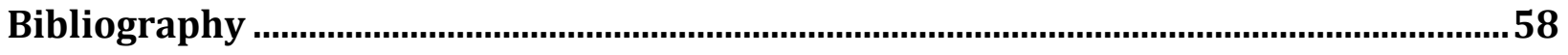




\section{List of Tables}

Table 1: Substrate specificity, tissue distribution and features of ENTs and CNTs ............14 


\section{List of Figures}

Figure 1: Purine and pyrimidine nucleosides................................................ 13

Figure 2: Predicted 2D membrane topologies of ENTs and CNTs.......................... 15

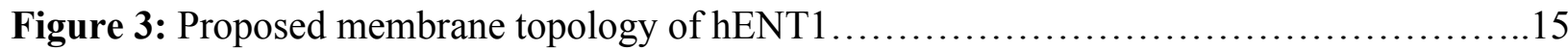

Figure 4: A putative AP2 recognition sequence, YQQL, in the intracellular loop between TM

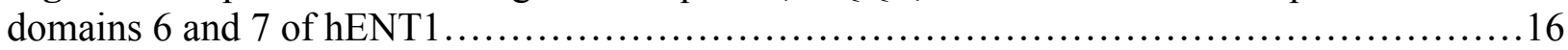

Figure 5: Endocytosis and recycling of plasma membrane proteins........................17

Figure 6: Gemcitabine's mechanism of action....................................... 18

Figure 7: Experimental design for 6- well plates used to grow and treat cells for the flow

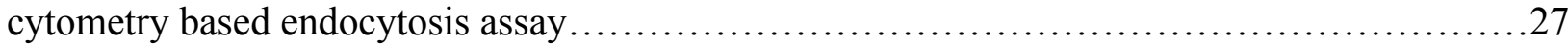

Figure 8: Experimental design for 6-well plates used to grow and treat cells for the microscopy

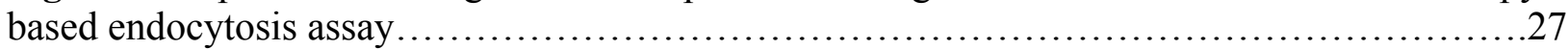

Figure 9: Annexin V (AV) and propidium iodide (PI) staining can be used to detect the

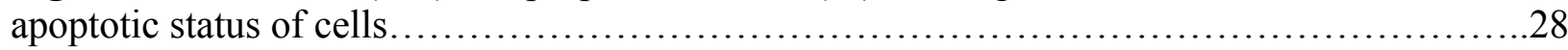

Figure 10: Experimental design for 6-well plates used to grow, treat and stain cells for the flow

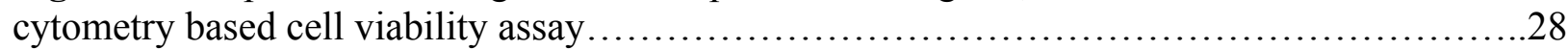

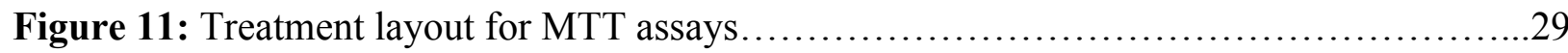

Figure 12: Surface level of HA-ENT1 decreases following treatment with cytidine...............36

Figure 13: Cytidine is not cytotoxic under the conditions used................................. 37

Figure 14: Effects of various transfection reagents on HEK cells............................ 38

Figure 15: Cytidine treatment leads to the formation of intracellular punctate structures.........39

Figure 16: HEK cells lose one of two NBTI binding sites following exposure to cytidine.......40

Figure 17: Cytidine exposure has no effect on subsequent hENT1-mediated nucleoside transport.

Figure 18: The redistribution of hENT1 away from the plasma membrane is not compensated

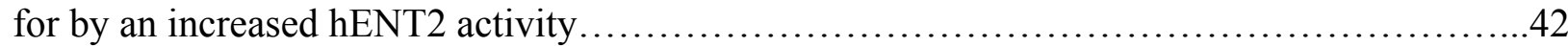

Figure 19: Hypoxanthine uptake is hENT2 mediated. HEK 293 cells........................43

Figure 20: Cytidine treatment leads to an increase in hENT1 mediated uptake rate and decreased

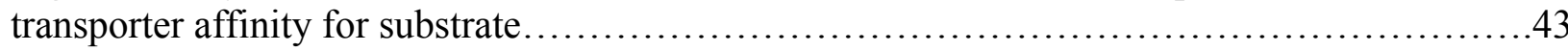

Figure 21: Cytidine pre-treatment leads to an increased cytotoxicity from gemcitabine in BxPC3

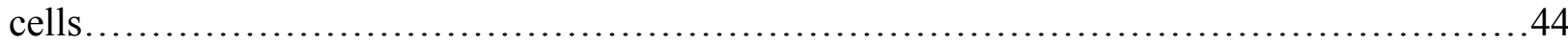

Figure 22: Representative dot plot of HEK cells treated with cytidine or fructose..............56

Figure 23: combined Scatchard plot for the cytidine and untreated conditions shown in Figure16 $\mathrm{B} \& \mathrm{C}$ 


\section{List of abbreviations}

$\mathrm{B}_{\max }-$ maximum binding

BxPC3- human pancreatic adenocarcinoma cells

CDA- cytidine deaminase

CKII- casein kinase 2

CNT- concentrative nucleoside transporter

CREB- cyclic AMP (cAMP) response element-binding protein, a transcription factor

DAT- dopamine transporter

DNA- deoxyribonucleic acid

ENT- equilibrative nucleoside transporter

FACS- fluorescence activated cell sorting

Fur4- uracil permease

GATA- transcription factor that binds to the "GATA" sequence in DNA

GLUT2- glucose transporter 2

HA- human influenza hemagglutinin, a protein tag

HEK293- human embryonic kidney cells

hENT1- human equilibrative nucleoside transporer

HIF-1- hypoxia-inducible factor-1, a transcription factor

IL-4- interleukin 4, a cytokine

$\mathrm{K}_{\mathrm{d}}-$ dissociation constant

kDa- kiloDalton

$\mathrm{K}_{\mathrm{m}}$ - Michalis- Menten constant, a measure of enzyme affinity for substrate

MAP kinase- Mitogen-activated protein kinase

MAZ- Myc-associated zinc finger protein, a transcription factor

Myc - protein tag derived from c-myc gene product (a transcription factor)

NA- nucleoside analog 
NBTI- S-(4-Nitrobenzyl)-6-thioinosine

NT- nucleoside transporter

PCR- polymerase chain reaction

PKA- protein kinase A

$\mathrm{PKC}$ - protein kinase $\mathrm{C}$

PM- plasma membrane

RNA- ribonucleic acid

RNR- ribonucleoside reductase

Sp-1- specificity protein 1 , a transcription factor

TM- transmembrane domain

$\mathrm{V}_{\max }-$ maximum rate of reaction/transport

WT- wild type 


\section{Introduction}

\section{Nucleosides}

A nucleoside consists of a nitrogen containing, ring-structured nucleobase attached to a pentose sugar (Figure 1A). The addition of up to three phosphate groups to a nucleoside gives rise to a nucleotide: the basic subunits of nucleic acids. A nucleotide that is attached to a ribose sugar is incorporated into RNA (ribonucleic acid), while a nucleotide containing a 2' deoxyribose is incorporated into DNA (deoxyribonucleic acid, Figure 1A). Nucleobases are divided into two categories depending on the ring structure: those with a single ring (a nitrogen containing heterocyclic, aromatic compound) are called pyrimidines while those with two rings (a pyrimidine ring fused to an imidazole ring) are called purines (Figure 1B,C). Interest in nucleosides began in the early 1920s when Leopold Cerecedo (1927) conducted studies on thymidine and uracil metabolism. Since then, numerous studies have explored the roles of nucleosides in nucleic acid synthesis, purinergic signaling, as energy providers, as therapeutic agents and more (Kalckar, 1950; Geiger et al, 1985; Pastor-Anglada et al, 1998). Purinergic signaling via adenosine receptors is a well-known cellular response that regulates the circulatory, renal, endocrine and nervous systems, among others (Rose and Coe, 2008). ATP and GTP serve as the energy providers for cellular processes such as metabolism and motility (Piomboni et al, 2012). The purine nucleoside, adenosine, serves as a cardioprotective stimulus during hypoxia and ischemia (Chaudary et al, 2002). For this reason, cardiac surgeries are often preceded by the administration of adenosine (Wei et al, 2001). A clinically important role of nucleoside analogs (NA) is use as cancer and anti-viral drugs (details in following sections).

Nucleosides need to be readily available because of the various important roles they play in the cell from providing energy for cellular metabolism to providing nucleosides for mRNA 
transcripts needed for protein synthesis. Cells can obtain nucleosides from two sources: salvage pathways and de novo synthesis. Most cells utilize both pathways although protozoan parasites and cells of the bone marrow and brain lack the cellular machinery for de novo synthesis of purines and rely on salvage pathways (King et al, 2006). Nucleoside salvage pathways are important in providing nucleosides for cellular processes because de novo synthesis of nucleosides is energy costly. Nucleosides are hydrophilic and cannot be taken up from the extracellular environment via simple diffusion and are therefore transported across cellular membranes by nucleoside transporters (NTs), SCL28 and SCL29.

\section{Nucleoside transporters}

\section{CNTs}

There are two known families of NTs, the equilibrative nucleoside transporters (ENTs) and the concentrative nucleoside transporters (CNTs). CNTs concentrate nucleosides inside the cells and the family consists of three members: CNT1-3. CNTs belong to the SCL28 gene family and are nucleoside- $\mathrm{Na}^{+}$symporters. While all three members transport uridine, CNT1 is a pyrimidine transporter, CNT2 is a purine transporter and CNT3 has a broad selectivity for purine and pyrimidine nucleosides (Young et al, 2013). The proposed structure of CNTs contains 13 transmembrane domains, an intracellular $\mathrm{N}$ terminus and extracellular $\mathrm{C}$ terminus (Figure 2). Currently, there are no crystal structures of any mammalian NTs. But recently, a Vibrio cholerae CNT (vcCNT) structure was reported, which shows that the transporter functions as a homotrimer (Johnson et al, 2012). As outlined in Table1, the three CNT members have differential tissue expression. 


\section{ENTs}

The $S L C 29$ gene family codes for equilibrative nucleoside transporters, of which there are four known members. ENTs are ubiquitously expressed, mediate bi-directional flux of nucleosides based on their concentration gradient, and work independent of any pre-existing gradients (Table 1). ENT 1-3 transport purines and pyrimidines and ENT2 also transports nucleobases (Baldwin et al, 2004). With the exception of ENT3, all ENTs are localized at the plasma membrane (Young et al, 2008). ENT3 is localized at intracellular membranes and can also transport the nucleobase adenine at pH 5.5 (Young et al, 2008). ENT4 is also known as the plasma membrane monoamine transporter (PMAT) because it is permeable to monoamine neurotransmitters, organic cations, and to adenosine at pH 5.5 (Young et al, 2008). ENTs are generally lower affinity nucleoside transporters compared to CNTs but they are especially important for NA drug efficacy because ENT1 for example, is the most widely distributed nucleoside transporter in human cells and tissues and is expressed at high levels compared to other transporters (Pennycooke et al, 2001).

\section{Nucleoside transporters as drug targets}

As of 2013, nine FDA approved anticancer NA drugs and over 25 anti-viral NA drugs existed (Jordheim et al, 2013). The first NAs approved for the treatment of cancer and viral infections were cytarabine (AraC) and edoxudine, respectively, in 1969. The rapid increase in the number of NA drugs reflects the evolution of resistance mechanisms against these drugs and also the limitations in their efficacy (Jordheim et al, 2013). These limitations arise from factors involved in the pharmacokinetics of these drugs, as well as pharmacogenomic factors. Pharmacokinetics is the study of the coordination of all proteins, particularly enzymes, involved in the mechanism of a drug's action (for example, Figure 6B). Pharmacogenomics is the discipline that investigates the genetic variations that affect the expression and function of 
proteins involved in drug effects, such as drug transporters, drug (including NA drug) metabolizing enzymes, etc. For example, a hyperactive deaminase that excessively inactivates the NA drug and allelic variations that result in a non-functional transporter would both result in poor drug efficacy (Figure 6B).

The wide range of NAs used in cancer and viral therapy is transported into the cells through the equilibrative and concentrative nucleoside transporters. These transporters have varying affinity for any given NA and the efficiency of uptake depends on the kind of transporters available in the target tissue. Individuals or cell types expressing low levels of nucleoside transporters, such as hENT1 (human ENT1), are unable to transport drugs in an expected manner and therefore, do not respond well to drug therapy (Gati et al, 1997). hENT1 is one of the major nucleoside transporters and is sufficient for the effective uptake of NA drugs (Mackey et al, 1998). One NA drug whose efficacy is dependent on the presence of hENT1 is gemcitabine, which is used as the front line treatment for pancreatic adenocarcinoma (Cavalcante and Monteiro, 2014).

Gemcitabine, or dFdC [4-amino-1-(2-deoxy-2,2-difluoro- $\beta$-D-erythropentofuranosyl)pyrimidin-2(1H)-on], is a cytidine analog in which fluorine atoms replace the two hydrogen atoms on the 2' carbon of the pentose ring (Figure 6A). It is administered intravenously over a period of 30 minutes and the dose depends on the size and type of cancer (Gemzar, 2013). Gemcitabine is transported into cells mainly by hENT1 (and to a lesser extent by hENT2, hCNT1 and hCNT3) and hENT1 presence is associated with longer survival after gemcitabine chemotherapy for pancreatic adenocarcinoma compared to patients with tumors without detectable hENT1 (Spratlin et al., 2004). After entry into cells, gemcitabine is phosphorylated to $\mathrm{dFdCTP}$, which is incorporated into the nascent DNA strand. When dFdCTP 
is incorporated into DNA, a single deoxynucleotide is incorporated afterwards, preventing chain elongation (Gandhi et al, 1996). This non-terminal position of gemcitabine makes DNA polymerases unable to proceed, in a process known as "masked chain-termination", which also inhibits removal of gemcitabine by DNA repair enzymes (Huang et al, 1991). Moreover, the diphosphate form of gemcitabine, $\mathrm{dFdCDP}$, blocks ribonucleotide reductase (RNR. Cavalcante and Monteriro, 2014). RNR transforms ribonucleotides into deoxyribonucleotides (dNTP) for incorporation in DNA. Inhibition of RNR leads to an imbalance in the dNTP pool, which also impedes DNA synthesis (Cavalcante and Monteriro, 2014).

\section{ENT1}

\section{Structure and Function}

ENT1 is currently the most studied nucleoside transporter of the SLC29 family. The putative structure of ENTs has 11 transmembrane domains (TM), with an intracellular N terminus and extracellular C terminus (Figure 3). Coded by the $S L C 29 A 1$ gene, ENT1 is a 456 amino acid long protein with a molecular weight of $50 \mathrm{kDa}$. There is a large extracellular loop between TM domains 1 and 2 of ENT1, which contains N-linked glycosylation sites (Vickers et al, 1999). TM domains 2, 4, 5 and 9-11 are reported to be critical for nucleoside transport (Endres and Unadkat 2005; SenGupta et al, 2002; Park and Hammond, 2012) and there is a large intracellular loop between TM domains 6 and 7, which serves as a regulatory hub for the transporter (details in following sections). An important feature of ENT1 is sensitivity to inhibition by the nucleoside analog, NBTI (S-(4-Nitrobenzyl)-6-thioinosine). NBTI inhibition of nucleoside transport is widely used to distinguish ENT1 from the other ENT isoforms because ENT1-dependent transport is sensitive to NBTI concentrations in the nanomolar range, while the 
other isoforms require relatively higher concentrations (micromolar range) for effective inhibition.

While the crystal structure of ENT1 has not been resolved yet, it is believed that ENT1 cycles through alternating conformations to translocate nucleosides. The Leishmania donovani nucleoside transporter 1.1 (LdNT1.1) is often used as a model for understanding the mechanism of action of ENTs. Computational modeling for extracelluar and intracellular closed conformations have been generated and tested by site-directed mutagenesis (Valdes et al, 2012; Valdes et al, 2014). These studies support the alternating conformations model such that the outward conformation binds nucleosides and a change in conformation leads to the opening of the transporter inside the cell, putting it in the inward conformation.

\section{Trafficking}

After translation, ENT1 is trafficked to the plasma membrane (possibly by recognition of a PM localization sequence). Because of their hydrophobic transmembrane domains, membrane proteins are trafficked to the target location in membrane-bound vesicles. These vesicles do not float freely through the cytosol; they are guided to the target location by cytoskeletal proteins, such as actin and microtubules (Racine et al, 2007). hENT1 is trafficked to the PM in association with microtubules and undergoes recycling in a clathrin dependent manner (Nivillac et al, 2011). Glycosylation of hENT1 at Asn48 (asparagine 48) is also required for PM localization. Substituting Asn with Glu (glutamic acid) results in imperfect PM localization and retention in the endomembrane network (Bicket and Coe, in prep).

\section{Regulation}

\section{Transcriptional regulation}

ENT1 is moderately well understood in terms of gene regulation. ENT1 contains consensus 
sequences for regulation by several transcription factors. The mENT1 (mouse ENT1) promoter possesses CREB, GATA-1 and Sp-1 consensus binding sites while the $h E N T 1$ promoter has MAZ, Sp-1 and IL-4 sites (Choi et al, 2000; Abdulla and Coe, 2007; Fernandez-Calotti et al, 2008). ENT1 transcription is down regulated in the brain and the heart by binding of HIF-1 to the ENT1 promoter (MoroteGarcia et al, 2009). The resulting decrease in plasma membrane hENT1 allows for an increase in the extracellular adenosine level, resulting in enhanced adenosine receptor dependent signaling leading to cardioprotective effects (Chaudary et al, 2004). In the placenta, high glucose and the consequent high nitric oxide (NO) levels signal for a down regulation of ENT1 transcription in a MAP kinase dependent manner (Munoz et al, 2006, Puebla et al 2008). Finally, while three mENT1 splice variants have been reported to date, there are no known splice variants for hENT1 (Choi et al, 2000; Robillard et al, 2008). However, the expression of hENT1 varies among individuals and cell types, suggesting transcriptional or posttranscriptional regulation (Pennycooke et al, 2001), which could impact response to NA drugs (Pennycooke et al, 2001). Clinically, quantitative PCR analyses of hENT1 mRNA in pancreatic cancer patients showed that those expressing lower levels of hENT1 mRNA had a poor prognosis when treated with gemcitabine (Giovannetti et al, 2006).

\section{Phosphorylation and protein-protein interactions}

Phosphorylation plays an important role in the regulation of any given protein. Proteins can be phosphorylated on intracellular serine, threonine and/or tyrosine residues by kinases (Amanchy et al, 2007) at any point after leaving the endoplasmic reticulum (ER) (Procino et al, 2003). Dephosphorylation is catalyzed by phosphatases and a balance between phosphorylation and dephosphorylation can regulate a target protein (Newton, 2003). The effect of phosphorylation may be an increased or decreased activity of the target protein. For example, 
while phosphorylation of serine 256 of aquaporin 2 (AQP2) by PKA in renal collecting ducts results in redistribution of protein from intracellular vesicles to the apical membrane, phosphorylation by PKC results in endocytosis and down regulation (van Balkom, 2002). Phosphorylation may occur at multiple residues within the target protein and by different kinases.

To date, three kinases are known to phosphorylate ENT1: PKC, PKA and CKII. While phosphorylation by PKA occurs on multiple serine residues within the protein, the intracellular loop between TM domains 6 and 7 contains confirmed PKC phosphorylation sites on serines 279, 281, 286 and threonine 274 (Reyes et al, 2011; Hughes et al 2015). PKC activation leads to an increased hENT1 affinity for substrate and therefore, increased substrate transport (Coe et al, 2002; Hughes et al, 2015). Activation of CKII leads to an increase in PM hENT1, which is accompanied by an increase in substrate uptake but shows altered NBTI (inhibitor) sensitivity (Bone et al, 2007). From the known hENT1 phosphosites, there is evidence of direct phosphorylation only for serine 281 by PKC (Hughes et al, 2015).

Protein-protein interactions (PPI) are another mechanism of protein regulation. The large intracellular loop of ENT1 between TM domains 6 and 7 contains putative sites for PPIs. A membrane yeast two-hybrid (MYTH) assay identified calmodulin (CaM) as an interacting partner of hENT1 and receptor activated calcium-dependent calmodulin binding of ENT1 was shown to influence ENT1-dependent transport of nucleosides (Bicket et al, submitted). The large intracellular loop also contains a putative AP-2 (a clathrin adaptor protein) binding site, YQQL, which suggests a clathrin mediated regulatory mechanism for hENT1 (Figure 4) (more details in following sections). 
In addition to the above factors, other regulatory mechanisms of hENT1, such as trafficking, may also decrease NA drug efficacy. An example of this is seen in the case of hepatitis $\mathrm{C}$ virus ( $\mathrm{HCV}$ ), which develops resistance to the most common and best treatment available: a combination of interferon (IFN) and ribaravin (or RBV, a guanosine analog). $\mathrm{HCV}$ induces autophagy (a regulatory mechanism in which portions of the PM are phagocytosed), which decreases hENT1 levels at the PM and also decreases clathrin levels. This, in turn, decreases hENT1 mediated RBV uptake and also interferes with routine hENT1 trafficking and recycling (Panigrahi et al, 2014).

\section{Substrate-dependent regulation and Endocytosis}

One mechanism of transporter internalization is via endocytosis and recycling. Briefly, endocytosis occurs when the plasma membrane invaginates around the membrane protein, capturing it in a coated vesicle. Endocytosis is also a way of internalizing bulk material from the extracellular environment and plasma membrane components, including the internalization of extracellular particles, fluid (pinocytosis), PM lipids and proteins (with/without their ligands), and pathogens (phagocytosis) (Grant and Donaldson, 2009). The removal of PM material is balanced by endosomal recycling pathways that return the endocytosed proteins and lipid to the membrane. Endocytosis is important for processes such as nutrient uptake, maintenance of functional proteins at the PM, signal transduction and more (Grant and Donaldson, 2009). The most common endocytic mechanism is clathrin-mediated endocytosis (CME) and all other mechanisms are classified as clathrin independent (Conner and Schmid, 2003).

In CME, specific cytoplasmic domains of cargo proteins are recognized by clathrin adaptors and packaged in clathrin-coated vesicles (CCV) that are brought into the cell. $\mathrm{CME}$ is widely studied and is facilitated by numerous accessory proteins (Doherty and McMahon, 2009). 
Some well-known examples of CME are the internalization of transferrin and low-density lipoprotein receptors (TfR and LDL, respectively). Iron bound transferrin binds to TfR and the entire receptor-ligand complex is internalized via $\mathrm{CME}$, delivering iron into the cell (Harding et al, 1983). Similarly, LDL particles bind to the LDL receptor and this complex also gets internalized via CME (Kibbey et al, 1998). Endocytosed vesicles are almost always delivered to early endosomes, where the cargo is sorted (Grant and Donaldson, 2009). These endosomes can mature into late endosomes and then fuse to the lysosomes if the cargo is to be degraded. Alternatively, the cargo can be sent to the trans-Golgi network for modification or back to the PM via recycling endosomal carriers (as in the case of the TfR) (Figure 5). Previous data suggest that hENT1 undergoes routine recycling likely via CME (Nivillac et al, 2011). Nivillac et al also showed that the entire life cycle of transiently transfected GFP-hENT1 takes 14 hours, ending with lysosomal degradation. An earlier study done with endogenously expressed ENT1 in chromaffin cells also reported that the transporter undergoes routine recycling and newly synthesized proteins are incorporated into the membrane every 33 hours (Torres et al, 1992). Endocytosis of membrane proteins contributes to cellular homeostasis by serving as a regulatory mechanism that either removes damaged/non-functional proteins, or maintains the intracellular concentration of a specific transporter's substrate (Nivillac et al 2011; Seron et al, 1999). Such endocytosis could either be triggered indirectly by another molecule, such as a hormone or kinase, or directly, by binding of the substrate itself. Internalization of the organic anion transporter, OAT1, is increased by activation of PKC, resulting in down regulated OAT1 activity (Zhang et al, 2008). Alternatively, a substrate can down regulate its own transporter, as seen in the case of the glucose transporter, GLUT2. Under high glucose conditions GLUT2 is internalized and degraded in the lysosomes (Hou et al, 2009). Similarly, endocytosis of hENT1 
could result in decreased drug efficacy as a consequence of decreased drug transport. We know that there is a basal level of hENT1 recycling to and from the membrane and it is possible that transporter internalization increases due to the bolus concentrations of substrate (NA drugs) used in chemotherapy. This means that NA drug uptake could decrease if the ratio between hENT1 internalization to incorporation in the PM increases as a regulatory response to high substrate concentration.

\section{Thesis rationale and hypothesis}

There are currently no reports in literature describing the fate of hENT1 upon repetitive substrate transport. If exposure to a bolus nucleoside concentration leads to changes in transporter function and/or regulation, limited NA drug efficacy may occur. There is evidence for substrate-dependent regulation of several other transport proteins, such as GLUT2, but the effect of prolonged exposure to a bolus nucleoside concentration on hENT1 function remains a gap in our knowledge regarding hENT1 regulation. I hypothesize that prolonged exposure to a bolus concentration of nucleosides leads to the redistribution of hENT1 away from the plasma membrane, which will lead to a decreased efficacy of gemcitabine.

I will test my hypothesis using a bolus concentration of cytidine on HEK293 cells. The reasons for this are: 1) because NA drugs cannot be used due to their cytotoxicity, 2) purine nucleosides would give rise to the possibility of purinergic receptor dependent effects and 3) using cytidine would allow to maintain consistency with the second part of the thesis: the effect of cytidine pre-treatment on gemcitabine-induced cytotoxicity (a cytidine analog). To further ensure that the results collected in this study are not just due to the presence of a solute, fructose will be used as an irrelevant substrate control (a negative control). For this control, a 
nucleos(t)ide solute, such as ATP or adenosine, cannot be used because of possible purinergic receptor dependent effects. Another common solute, glucose, cannot be used because the culture medium (DMEM) already contains a considerable amount of glucose $(25 \mathrm{mM})$.

Changes in transporter abundance at the PM can be confirmed via flow cytometry, microscopy and NBTI binding assays and changes in transporter function can be investigated via transport assays. The effect of cytidine pre-treatment on the efficacy of gemcitabine can be measured via the MTT-based cytotoxicity assay. If my hypothesis that prolonged exposure to elevated amounts of cytidine leads to increased hENT1 internalization is correct, I will see a decrease in total PM hENT1 level, accompanied by a decrease in subsequent substrate uptake and therefore, a decrease in gemcitabine-induced cytotoxicity. Results other than these would suggest a different regulatory mechanism or that the system is more complex than expected (i.e there could be internalization but there could be compensatory mechanisms that mask it). 
A.

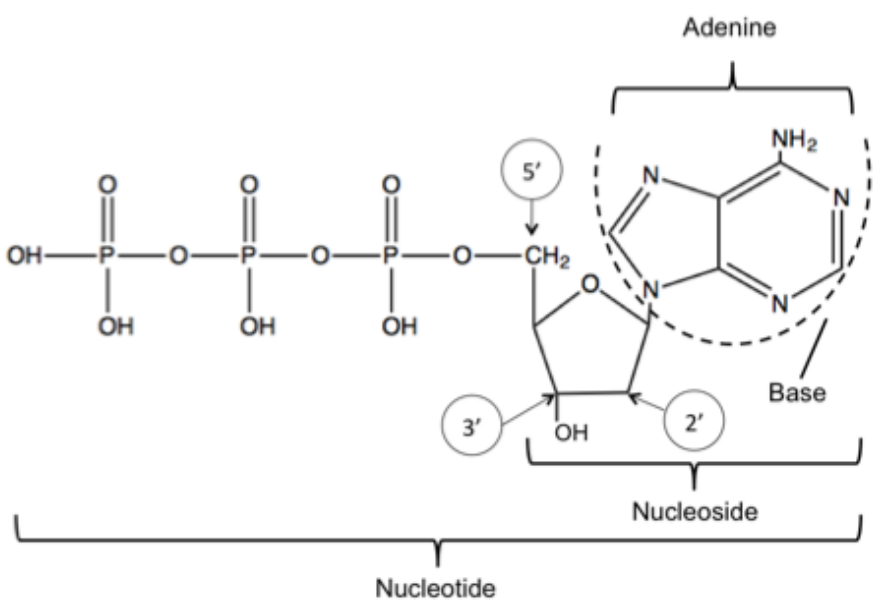

B.

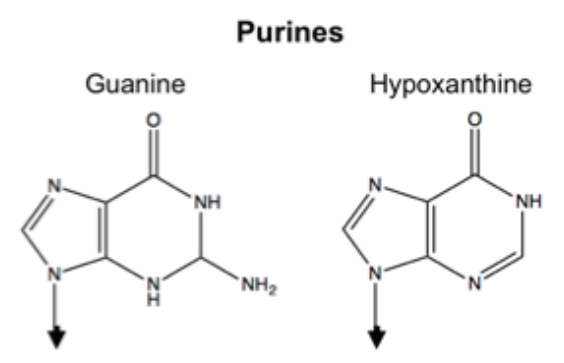

c.

Pyrimidines
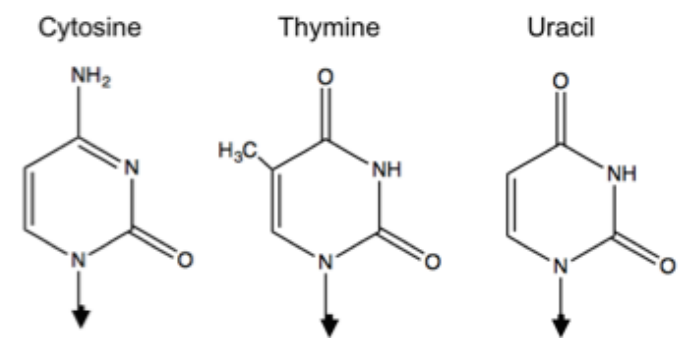

Figure 1: Purine and pyrimidine nucleosides. A) Structure of a nucleobase, nucleoside and nucleotide. Nucleosides with a 2' and 3' hydroxyl (-OH) group in the pentose sugar ring are called ribonucleosides, while those with only a $3^{\prime} \mathrm{OH}$ are called deoxyribonucleosides. Nucleotides can have 1-3 phosphate groups attached to the 5' carbon of the pentose ring (deoxyadenosine triphosphate shown in this example). B) Common, naturally occurring purines (including adenine shown in A) and C) pyrimidines. Arrows denote the position of bond formation with pentose sugar. 
Table 1: Substrate specificity, tissue distribution and features of ENTs and CNTs.

${ }^{\mathrm{a}}$ Young et al, 2012

${ }^{b}$ Young et al, 2008

\begin{tabular}{|c|c|c|c|}
\hline NT & Substrate & $\begin{array}{c}\text { Tissue } \\
\text { distribution }^{\mathrm{a}}\end{array}$ & $\begin{array}{l}\text { Distinguishing/unique } \\
\text { feature }^{\mathrm{b}}\end{array}$ \\
\hline CNT1 & $\begin{array}{l}\text { Pyrimidine } \\
\text { nucleosides }\end{array}$ & $\begin{array}{c}\text { Kidney, liver, small } \\
\text { intestine }\end{array}$ & Substrate specificity \\
\hline $\mathrm{CNT} 2$ & $\begin{array}{l}\text { Purine nucleosides } \\
\text { and uridine }\end{array}$ & $\begin{array}{c}\text { Heart, skeletal } \\
\text { muscle, liver, } \\
\text { kidney, intestine, } \\
\text { pancreas, placenta } \\
\text { and brain }\end{array}$ & Substrate specificity \\
\hline CNT3 & $\begin{array}{c}\text { Pyrimidine and } \\
\text { purine nucleosides }\end{array}$ & $\begin{array}{l}\text { Widely expressed } \\
\text { but most abundant } \\
\text { in mammary gland, } \\
\text { pancreas, bone } \\
\text { marrow, trachea and } \\
\text { intestine }\end{array}$ & $\begin{array}{l}\text { Can use the } \mathrm{Na}^{+} \text {or } \mathrm{H}^{+} \\
\text {gradient for nucleoside } \\
\text { co-transport }\end{array}$ \\
\hline
\end{tabular}

\begin{tabular}{|c|c|c|c|}
\hline ENT1 & $\begin{array}{c}\text { Pyrimidine and } \\
\text { purine nucleosides }\end{array}$ & Ubiquitous & $\begin{array}{l}\text { Very sensitive to } \\
\text { inhibition by NBTI }\end{array}$ \\
\hline ENT2 & $\begin{array}{l}\text { Pyrimidine and } \\
\text { purine nucleosides } \\
\text { and nucleobases }\end{array}$ & Ubiquitous & $\begin{array}{c}\text { Nucleobase } \\
\text { transporter, role in } \\
\text { nuclear membrane }\end{array}$ \\
\hline ENT3 & $\begin{array}{c}\text { Pyrimidine and } \\
\text { purine nucleosides } \\
\text { and adenine (at } \mathrm{pH} \\
5.5 \text { ) }\end{array}$ & Ubiquitous & $\begin{array}{c}\text { Intracellular membrane } \\
\text { localization, activity is } \\
\text { pH dependent }\end{array}$ \\
\hline ENT4 (PMAT) & $\begin{array}{l}\text { Adenosine (at } \mathrm{pH} \\
\text { 5.5) and organic } \\
\text { cations, including } \\
\text { serotonin }\end{array}$ & Ubiquitous & $\begin{array}{c}\mathrm{pH} \text { dependent } \\
\text { adenosine transport, } \\
\text { transports organic } \\
\text { cations }\end{array}$ \\
\hline
\end{tabular}




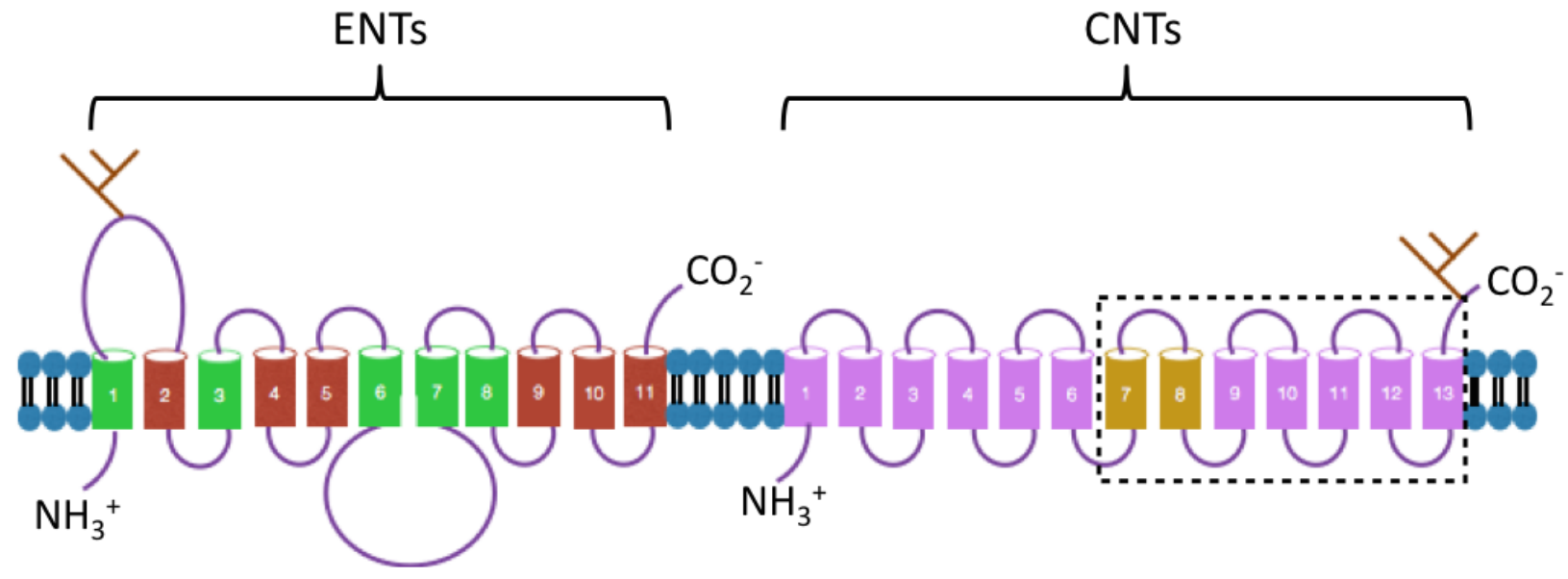

Cytoplasm

\begin{tabular}{|c|c|}
\hline Y N-linked oligosaccharide chain & $\begin{array}{l}\text { Helix implicated in permeant } \\
\text { selectivity in CNTs }\end{array}$ \\
\hline $\begin{array}{l}\text { Helix implicated in permeant } \\
\text { or inhibitor binding in ENTs }\end{array}$ & $\begin{array}{l}\text { Region implicated in } \\
\text { cation-coupling in CNTs }\end{array}$ \\
\hline
\end{tabular}

Figure 2: Predicted 2D membrane topologies of ENTs and CNTs.

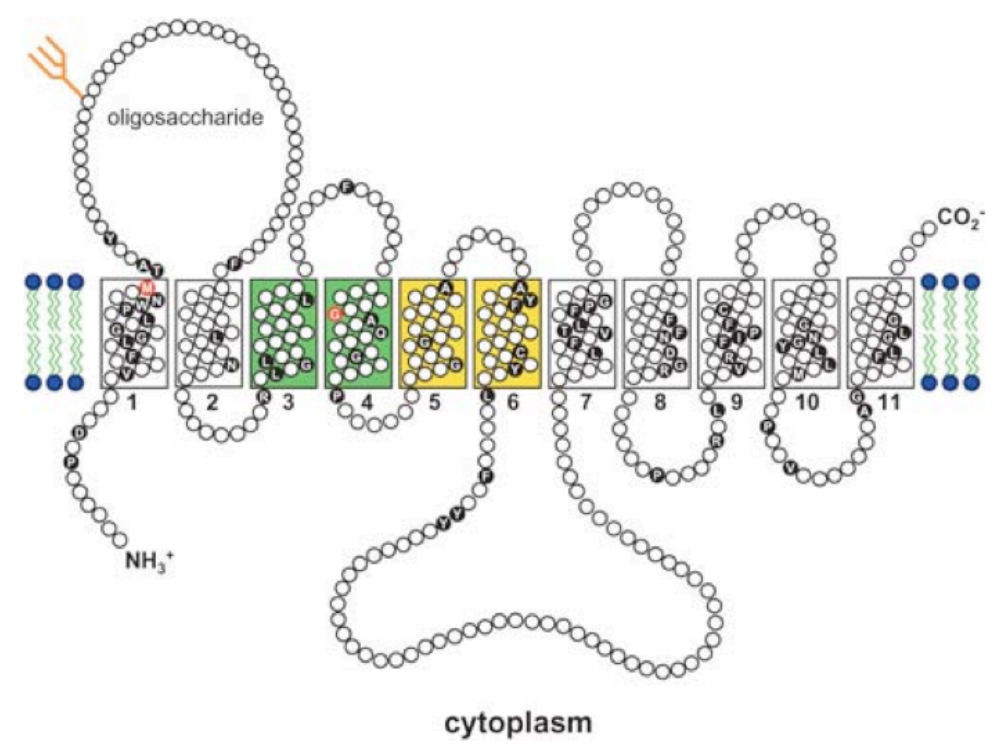

Figure 3: Proposed membrane topology of hENT1. Image adapted from Baldwin et al, 2004. 


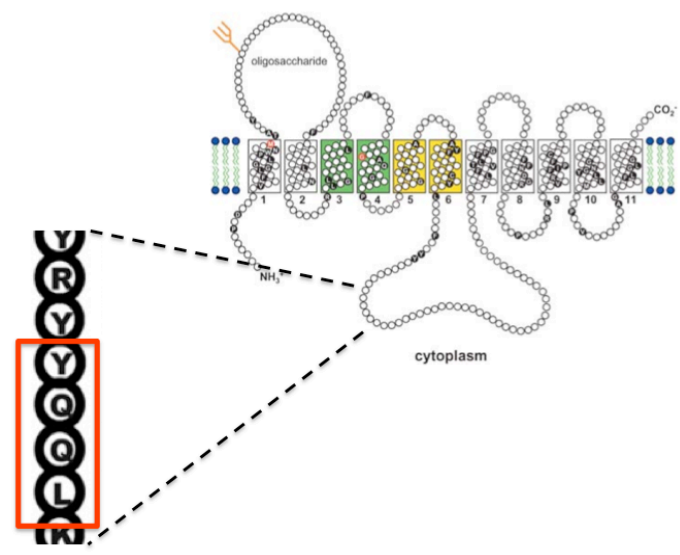

Figure 4: A putative AP2 recognition sequence, YQQL, in the intracellular loop between TM domains 6 and 7 of hENT1. 


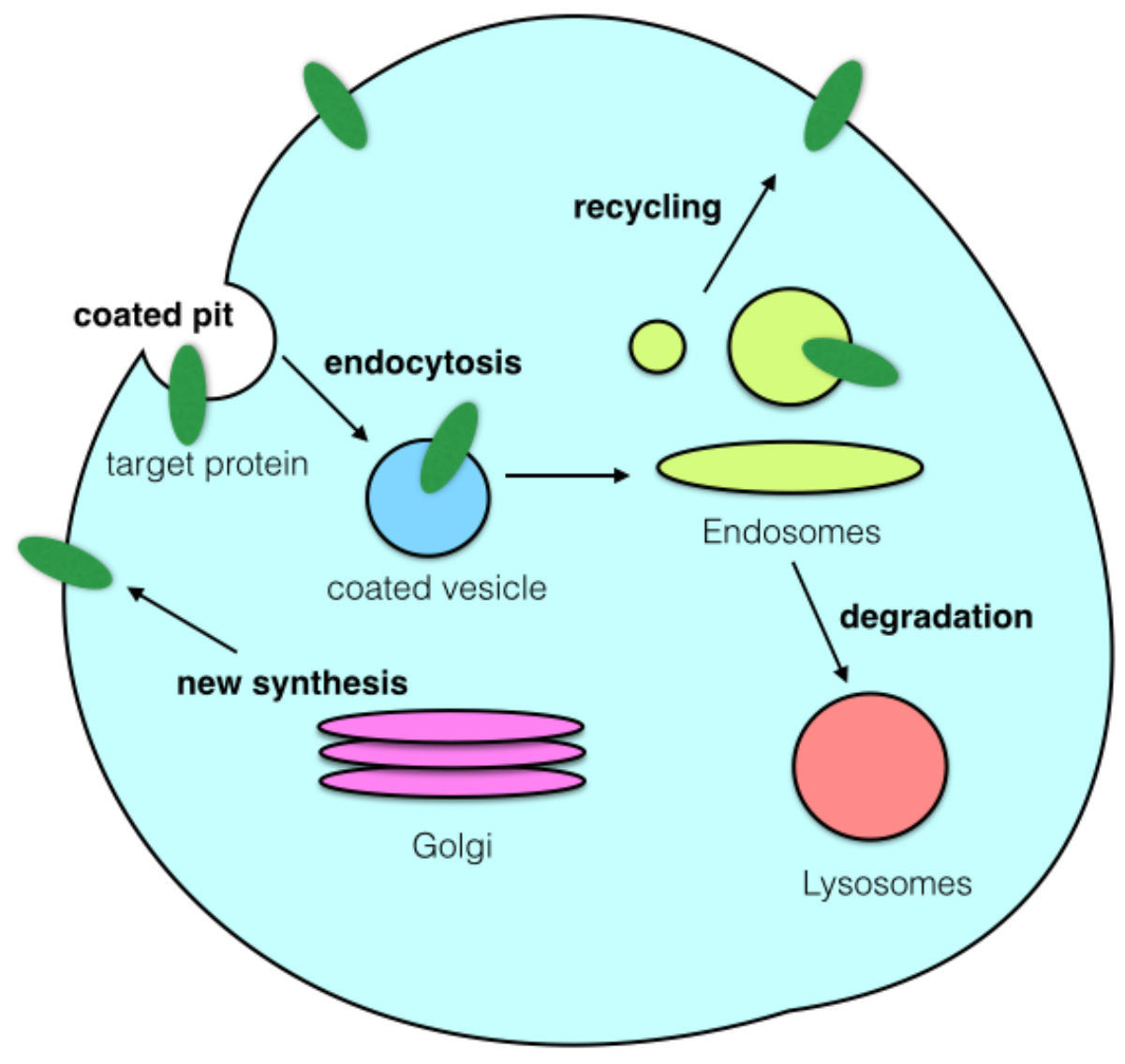

Figure 5: Endocytosis and recycling of plasma membrane proteins. The invagination of the PM around a target protein captures it in a coated vesicle. The membrane protein can be sent back to the PM (recycling), the vesicles can mature into endosomes and fuse to lysosomes (degradation) or the target protein can be modified in the golgi bodies before being sent back to the PM. 
A.<smiles>Nc1ccn(C2OC(CO)C(O)C2(F)F)c(=O)n1</smiles>

Gemcitabine

B.

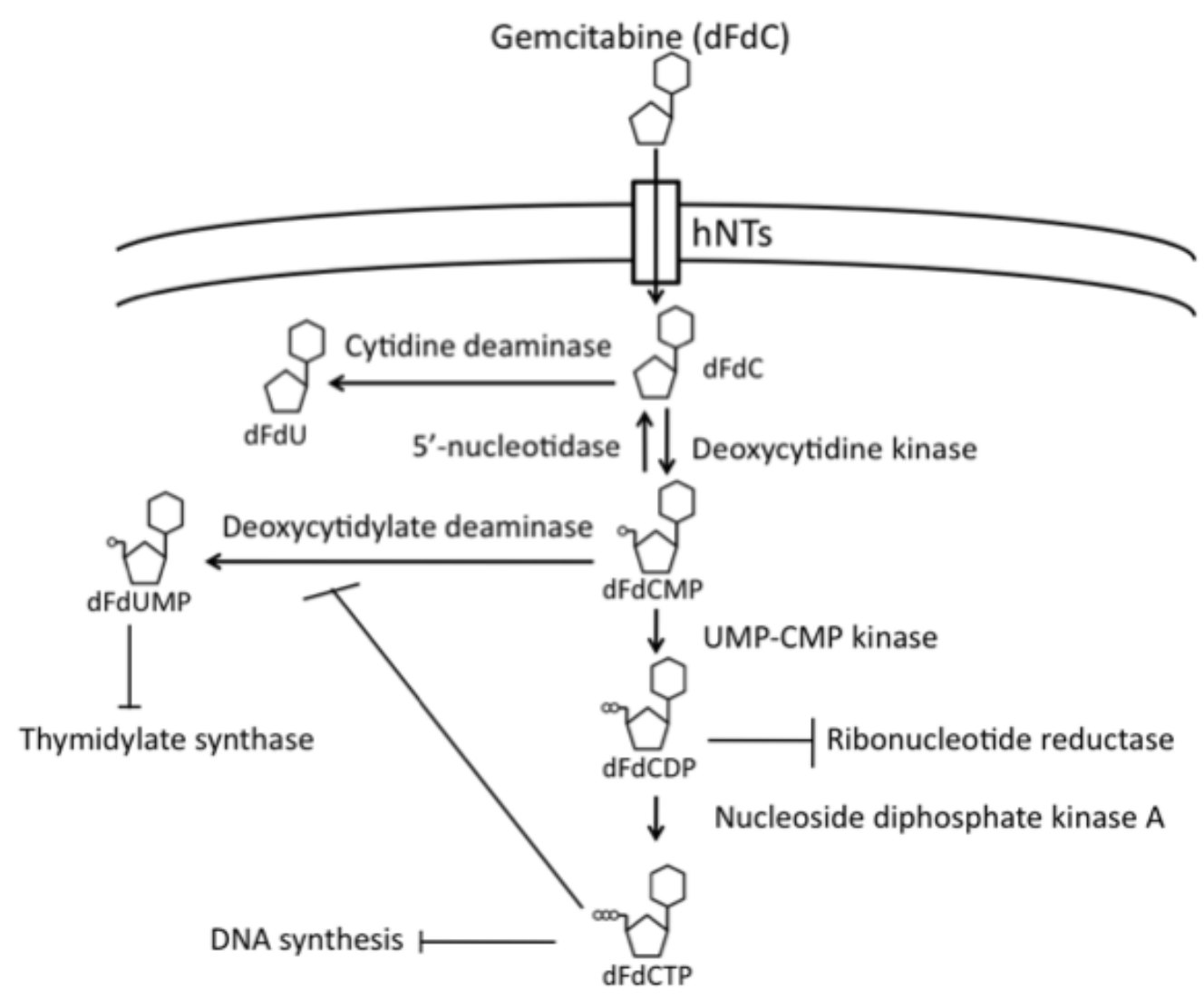

Figure 6: Gemcitabine's (A) mechanism of action (B). 


\section{Materials and Methods}

Cytidine, fructose, 2-chloroadenosine, hypoxanthine, dipyridamole (DIPY), and S-(4Nitrobenzyl)-6-thioinosine (NBTI) were purchased from Sigma Aldrich. $\left[{ }^{3} \mathrm{H}\right]$ NBTI, $\left[{ }^{3} \mathrm{H}\right]$ 2-chloroadenosine and $\left[{ }^{3} \mathrm{H}\right]$ hypoxanthine were purchased from Moravek Biochemicals Brea, California. Rat monoclonal anti-HA antibody was purchased from Roche (Cat\#11867423001); HA-tag mouse monoclonal antibody Alexa Fluor 488 was purchased from NewEngland BioLabs (Cat\# 2350S) and Donkey anti-rat IgG Alexa Flour 488 was purchased from Life technologies (Cat\# A21208). V450 Annexin V and propidium iodide were purchased from BD Horizon. For protein quantification, the Bio-Rad DC Protein Assay Kit II was used.

\section{Cell culture}

HEK293 and BxPC3 cell cultures were maintained in 10cm plates in Dulbecco's Modified Eagle Medium (DMEM) (Gibco) or RPMI-1640 medium, respectively, supplemented with $10 \%(\mathrm{v} / \mathrm{v})$ Fetal Bovine Serum (FBS) (Gibco) at $37^{\circ} \mathrm{C}$ with $5 \%(\mathrm{v} / \mathrm{v}) \mathrm{CO}_{2}$.

Upon reaching $100 \%$ confluency, cells were passed and seeded into new plates. Briefly, the old medium was aspirated, followed by washing once with $4 \mathrm{~mL} 1 \mathrm{x}$ PBS. The cells were detached with $3 \mathrm{~mL}$ trypsin, followed by the addition of $4 \mathrm{~mL}$ supplemented medium (medium + $10 \% \mathrm{FBS}$ ) to arrest trypsin activity. Cells were collected and pelleted at 1000xg for 2 minutes.

The supernatant was aspirated away and the pellet was resuspended in fresh supplemented medium. The cell suspension was diluted according to the required seeding density and plated on new, sterile $10 \mathrm{~cm}$ plates. Stocks were seeded at a density of $2.3 \times 10^{6}$ cells $/ \mathrm{mL}$; seeding densities for specific plate formats are later defined for their corresponding experiments. 


\section{Poly-D-lysine coating}

Cell culture plates were coated with poly-D-lysine for microscopy experiments and transport assays. Poly-D-lysine (Cat\# P7405-5MG) was diluted 20x in double distilled water $\left(\mathrm{ddH}_{2} \mathrm{O}\right)$. Enough diluted reagent was applied to cell culture plates to cover their entire surface. Following incubation at room temperature for 5 minutes, the reagent was aspirated away and the plate was washed once with $\mathrm{ddH}_{2} \mathrm{O}$. The coated plates were left in the $37^{\circ} \mathrm{C}$ incubator for $1-2$ hours to dry before seeding cells in them.

\section{Generation of HA-hENT1 construct}

An HA tag was cloned, in frame, into the hENT1 coding sequence (CDS) after the amino acid at position 64 (highlighted in the CDS below). In the protein structure, this tag is located in the first extracellular loop. The sequence was submitted to DNA 2.0 for generation of a mammalian expression vector with the HA-hENT1 gene cloned in it.

1 MTTSHQPQDR YKAVWLIFFM LGLGTLLPWN FFMTATQYFT NRLDMSQNVS LVTAELSKDA

61 QASAYPYDVP DYAAPAAPLP ERNSLSAIFN NVMTLCAMLP LLLFTYLNSF LHQRIPQSVR

121 ILGSLVAILL VFLITAILVK VQLDALPFFV ITMIKIVLIN SFGAILQGSL FGLAGLLPAS

181 YTAPIMSGQG LAGFFASVAM ICAIASGSEL SESAFGYFIT ACAVIILTII CYLGLPRLEF

241 YRYYQQLKLE GPGEQETKLD LISKGEEPRA GKEESGVSVS NSQPTNESHS IKAILKNISV

301 LAFSVCFIFT ITIGMFPAVT VEVKSSIAGS STWERYFIPV SCFLTFNIFD WLGRSLTAVF

361 MWPGKDSRWL PSLVLARLVF VPLLLLCNIK PRRYLTVVFE HDAWFIFFMA AFAFSNGYLA

421 SLCMCFGPKK VKPAEAETAG AIMAFFLCLG LALGAVFSFL FRAIV*

\section{Transformation of plasmid DNA in DH5a (E-coli)}

HA-hENT plasmid DNA $(0.5-5 \mu \mathrm{L})$ was added to $15 \mu \mathrm{L}$ competent cells (Subcloning Efficiency ${ }^{\mathrm{TM}} \mathrm{DH} 5 \alpha^{\mathrm{TM}}$ Competent Cells from Invitrogen) and left on ice for 30 minutes (a higher volume of bacteria and plasmid DNA were required when using low concentrations of less pure plasmid DNA). After 30 minutes, bacteria were heat shocked at $42^{\circ} \mathrm{C}$ for 45 seconds on a thermoblock, and then placed on ice for 2 minutes. LB broth $(100-900 \mu \mathrm{L})$ was added to this

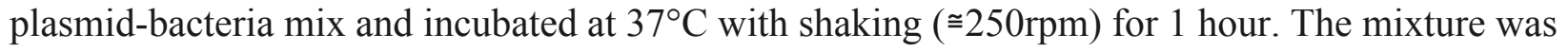


then subjected to a quick spin (about 15 seconds at $14000 \mathrm{x}$ g) to pellet the cells. The cells were resuspended in $40 \mu \mathrm{L}$ of the supernatant, plated on LB-agar plates containing Ampicillin $(100 \mu \mathrm{g} / \mathrm{mL})$ and incubated (inverted) at $37^{\circ} \mathrm{C}$ overnight.

\section{Maxiprep Plasmid Isolation}

For transfection, highly pure and concentrated DNA was prepared using commercial maxiprep plasmid isolation kits (EndoFree Plasmid Maxi Kit from Qiagen). A 3mL (3mL LB containing $100 \mu \mathrm{g} / \mathrm{mL}$ Ampicillin) culture of HA-hENT1 transformants (from glycerol stock) was grown overnight at $37^{\circ} \mathrm{C}$ with shaking at $\cong 250 \mathrm{rpm}$. The next morning, the culture was used to inoculate a larer volume of media $(100 \mu \mathrm{L}$ of overnight culture in $100 \mathrm{ml} \mathrm{LB}$ containing $100 \mu \mathrm{g} / \mathrm{mL}$ Ampicillin) and grown for 8-16 hours under the same conditions. Plasmid DNA was extracted from this culture and quantified using the NanoDrop 2000 Spectrophotometer (260 $\mathrm{nm})$.

\section{Transfection}

Lipofectamine $^{\circledR} 3000$ (Invitrogen) was used as the transfecting reagent. Lipofectamine has cationic lipid molecules that entrap the negatively charged plasmid DNA and form a liposome. The liposomes fuse with the cell membrane, allowing release of the plasmid DNA into the cell. The manufacturer's protocol was optimized for the amounts of DNA and Lipofectamine in a 6-well plate format. For a 6-well plate $(2 \mathrm{~mL}$ culture medium/well), the volumes of DNA and Lipofectamine that resulted in optimal transfection were determined to be $2.5 \mu \mathrm{g}$ and $7.5 \mu \mathrm{L}$, respectively. Cells were seeded at a density of $0.45 \times 10^{6}$ cells $/ \mathrm{mL}$, transfected the next day in culture medium (medium $+10 \% \mathrm{FBS}$ ) according to manufacturer's protocol and used for experiments 21-24 hours post-transfection. (Note: Lipofectamine 3000 works with supplemented and non-supplemented media. It is also not required to change the medium after transfection). 


\section{NBTI bindings}

NBTI is a nucleoside analog, which binds to ENTs and inhibits nucleoside flux. When present in the nM range, NBTI specifically binds to ENT1 with very high affinity and the number of NBTI binding sites can be used as a measure of ENT1 abundance at the membrane.

HEK293 cells seeded at $4 \times 10^{6}$ cells $/ \mathrm{mL}$ in $10 \mathrm{~cm}$ plates were treated with $40 \mu \mathrm{M}$ cytidine for 6 hours in non-supplemented medium (DMEM). Following treatment cells were washed with PBS, collected by scraping from the plate and resuspended in binding buffer (10mM Tris- $\mathrm{HCl}$, $100 \mathrm{mM} \mathrm{KCl}, 0.1 \mathrm{mM} \mathrm{MgCl} 2,0.1 \mathrm{mM} \mathrm{CaCl}_{2}$ (pH 7.4)). NBTI binding experiments were performed in the presence of increasing $\left[{ }^{3} \mathrm{H}\right] \mathrm{NBTI}$ concentrations $(0.186 \mathrm{nM}-7.45 \mathrm{nM})$. Specific binding was calculated by subtracting the binding measured in the presence of $10 \mu \mathrm{M}$ unlabelled NBTI. Cells were incubated with $\left[{ }^{3} \mathrm{H}\right] \mathrm{NBTI}$ for 50 minutes at room temperature to reach equilibrium binding, which was stopped by adding ice cold binding buffer. All samples were filtered through Whatman (Kent, U.K.) GF/B glass microfiber disks using a vacuum manifold Millipore system, and the discs were then washed twice with the same buffer. Filter discs were placed in vials with scintillation fluid and accumulated radioactivity was measured by standard scintillation counting. [3H]NBTI binding constants ( $\mathrm{Kd}$ and Bmax) were obtained using nonlinear regression analysis (GraphPad, PRISM).

To confirm whether Scatchard plots generated a straight or curvilinear profile, goodness of fit tests were considered for linear and non-linear regression analyses, both. The type of analysis (linear vs non-linear) that gave an $\mathrm{R}^{2}$ of 0.8 or higher was accepted.

\section{Endocytosis assays}

\section{Flow cytometry}

Flow cytometry is a fast and reliable technique for measuring physical and chemical characteristics of single cells in suspension. In a flow cytometer, cells flow through a nozzle 
narrow enough that cells flow through it in single file. As the cells flow, they pass a beam of laser light, which gets scattered upon cell contact. The pattern of scattered light is picked up by detectors positioned infront of the light beam (measuring forward scatter) and to the sides of the beam (measuring side scatter). Because specific wavelengths can be used to excite target fluorophores, fluorophore conjugated antibodies can be used to detect changes in abundance of a protein of interest.

HEK293 cells seeded at $0.45 \times 10^{6}$ cells $/ \mathrm{mL}$ were transfected the next day with HAhENT1. 21-24 hours after transfection, cells were treated with either $40 \mu \mathrm{M}$ cytidine or $40 \mu \mathrm{M}$ fructose for 6 hours in non-supplemented medium (in the 6-well format, Figure 7), followed by immunofluorescence labeling with Alexa Fluor 488 conjugated Anti-HA antibody (NewEngland BioLabs) for 20 minutes at room temperature. This was followed by flow cytometric analysis using the MACSQuant ${ }^{\circledR}$ Instrument (Miltenyi Biotec). Since the HA tag is in the first extracellular loop of hENT1, surface fluorescence (using anti-HA antibody to label intact cells) was measured to quantify hENT1 abundance. Fructose was used as an irrelevant substrate control to ensure that the observed results are in fact due to cytidine only and not just because of the presence of a solute.

\section{Microscopy}

While flow cytometry is a valuable technique that can be used to quantify endocytosis, it does not provide any visual information. Therefore, confocal microscopy was used to confirm and visualize hENT1 internalization. Cells were grown on coverslips in a 6 well plate (poly-Dlysine coated coverslips) at $0.45 \times 10^{6} \mathrm{cell} / \mathrm{mL}$ and transfected with HA-hENT1 the next day. Following transfection (21-24 hours), anti-HA antibody (1:1000; Roche) was added to cells for 
one hour, on ice (in supplemented medium). Unbound antibody was washed away with PBS, followed by the addition of $40 \mu \mathrm{M}$ cytidine or $40 \mu \mathrm{M}$ fructose ( 6 well format, Figure 8 ). The plates were placed back in the incubator $\left(37^{\circ} \mathrm{C}, 5 \% \mathrm{CO}_{2}\right)$ for 6 hours.

After treatment, cells were fixed with $4 \%(\mathrm{w} / \mathrm{v})$ paraformaldehyde (15 minutes at room temperature), followed by probing with Donkey anti-rat IgG Alexa Flour 488 (1:2000) and staining nuclei with DAPI (Life Technologies) according to manufacturer's protocol. Coverslips were mounted, cell side down, on glass slides with DAKO mounting medium (Dako-Agilent Technologies). All slides were viewed at St Michaels' Hospital BioImaging Core Facilities (Li Ka Shing Knowledge Institute) using the Zeiss LSM 700 Inverted Confocal microscope $(63 \times$ oil immersion lens, 1.4 N.A). A minimum of 6-7 fields of view were analyzed and confocal images show a single, representative section of a Z-series taken through the entire cell.

\section{Transport assay:}

To measure nucleoside uptake (2-chloroadenosine or hypoxanthine) following cytidine treatment, HEK293 cells were seeded at 0.6 cells $/ \mathrm{mL}$ in 6 well plates (poly-D-lysine coated) and treated with $40 \mu \mathrm{M}$ cytidine, $40 \mu \mathrm{M}$ fructose or left untreated, each condition in a separate plate. Following treatment, cells were washed once with $\mathrm{Na}^{+}$free transport buffer $(20 \mathrm{mM}$ Tris-HCl, 3 $\mathrm{mM}$ potassium diphosphate, $1 \mathrm{mM}$ magnesium chloride, $2 \mathrm{mM}$ calcium chloride, $5 \mathrm{mM}$ glucose, $130 \mathrm{mM} N$-methyl D- glucamine (pH 7.4)) and incubated for 10 seconds with permeant solution made in the same buffer containing $10 \mu \mathrm{M} 2$-chloroadenosine and $\left[{ }^{3} \mathrm{H}\right] 2$-chloroadenosine (20Ci/mmol) or $10 \mu \mathrm{M}$ hypoxanthine and $\left[{ }^{3} \mathrm{H}\right]$ hypoxanthine $(20.3 \mathrm{Ci} / \mathrm{mmol})$. The uptake was stopped by quickly aspirating away permeant and washing three times with ice-cold stop buffer (100nM NBTI and $30 \mu \mathrm{M}$ DIPY in $\mathrm{Na}^{+}$free transport buffer). The cells were lysed in $2 \mathrm{M} \mathrm{NaOH}$ (20 minutes with shaking at room temperature, followed by storage overnight at $4{ }^{\circ} \mathrm{C}$ ) and 
radioactivity accumulated due to substrate transport was measured by standard scintillation counting, after neutralization with $6 \mathrm{~N} \mathrm{HCl}$.

\section{Kinetic assay:}

To measure kinetic parameters $\left(\mathrm{V}_{\max }\right.$ and $\left.\mathrm{K}_{\mathrm{m}}\right)$ of $\mathrm{hENT}$-mediated 2-chloroadenosine uptake, HEK cells were seeded and treated as described above for transport assays. Following treatment, transport assays were performed as described above but uptake was measured for 5 seconds for increasing concentrations of 2-chloroadenosine: $5,10,50,100,250$, and $500 \mu \mathrm{M}$.

\section{Cell Viability assays}

\section{Flow Cytometry}

A flow cytometry based assay using annexin $\mathrm{V}$ and propiduim iodide (PI) can be used to determine the apoptotic status/viability of cells (Figure 9). In viable cells, phosphotidylserine (PS) is present only in the inner leaflet of the plasma membrane. However, when cells are undergoing early apoptosis, some PS molecules translocate to the outer leaflet and the PS binding protein, annexin V, can bind to these exposed PS molecules. Taking advantage of this, fluorophore labeled annexin $\mathrm{V}$ can be used to detect cells undergoing early apoptosis. When a cell enters the late apoptotic stage, its plasma membrane looses integrity and becomes permeable. Therefore, positive staining for DNA binding molecules (by dyes which can only enter permeable cells), such as propidium iodide, is characteristic of cells undergoing late apoptosis. In this way, a combination of fluorophore labeled annexin V and PI staining can be used to assess cell viability.

For this assay, HEK293 cells were seeded at 0.45 cells $/ \mathrm{mL}$ and treated as described for the flow cytometry based endocytosis assay. Following treatment, cells were harvested and resuspended in annexin binding buffer (10mM Hepes ( $\mathrm{pH} 7.4), 140 \mathrm{mM} \mathrm{NaCl}, 2.5 \mathrm{mM} \mathrm{CaCl} 2$ ). 
V450 Annexin V (BD Horizon) was added to cells and they were kept on ice for 20 minutes. PI (BD Horizon) was added to these samples just before flow cytometric analysis (since cells should not be left with PI for long durations because it is cytotoxic). To measure background staining, cells were either left unstained, stained with Annexin V only, or stained with PI only (6well format, Figure 10).

\section{MTT (3-(4, 5-dimethylthiazolyl-2)-2, 5-diphenyltetrazolium bromide) assay}

The reduction of tetrazolium salts by metabolically active cells produces colored products, which allows for the measurement of cell viability. MTT is a yellow colored tetrazolium salt, which produces a purple product (formazan) when it is reduced. The intracellular formazan can be solubilized using DMSO or detergent containing buffers and the absorbance of the solution can be quantified with a spectrophotometer. By comparing the absorbance to a control, which consists of healthy cells (i.e not treated with cytotoxic reagent), the percentage of cells that are viable can be calculated.

For MTT assays, BxPC3 cells were seeded in a 96 well plate at a density of 8000 cells/well (Figure 11). Following 48 hours, cells were treated with $40 \mu \mathrm{M}$ cytidine for 6 hours, washed with serum free medium (RPMI-1640) and treated with gemcitabine (66nM and 100nM). Following 48 hours of gemcitabine treatment, the old medium was aspirated and cells were incubated with MTT (dissolved in cell-specific culture medium, i.e. RPMI-1640) at $37^{\circ} \mathrm{C}$ for 45 minutes. The purple crystals were solubilized by the addition of DMSO and absorbance was measured at $550 \mathrm{~nm}$. 


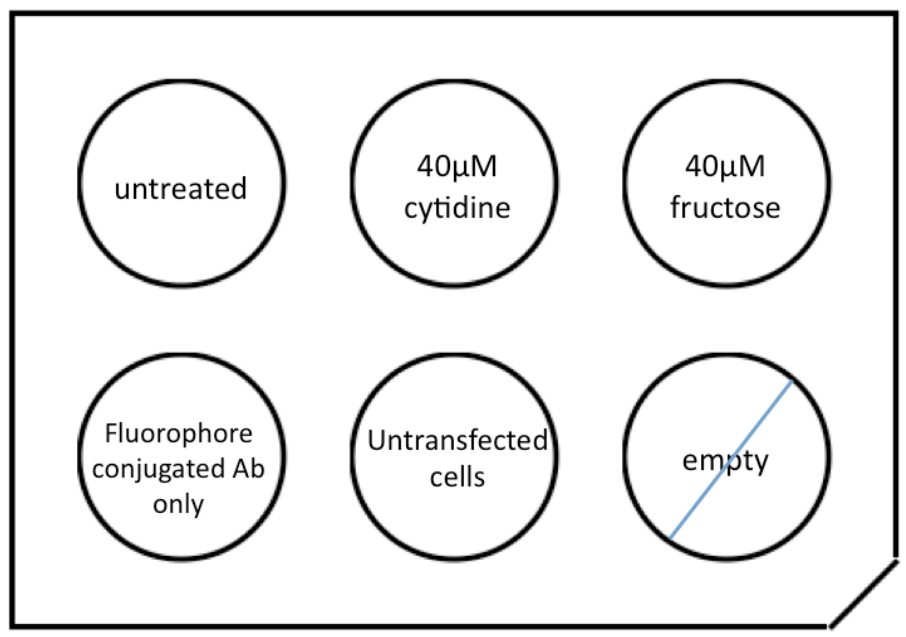

Figure 7: Experimental design for 6- well plates used to grow and treat cells for the flow cytometry based endocytosis assay.

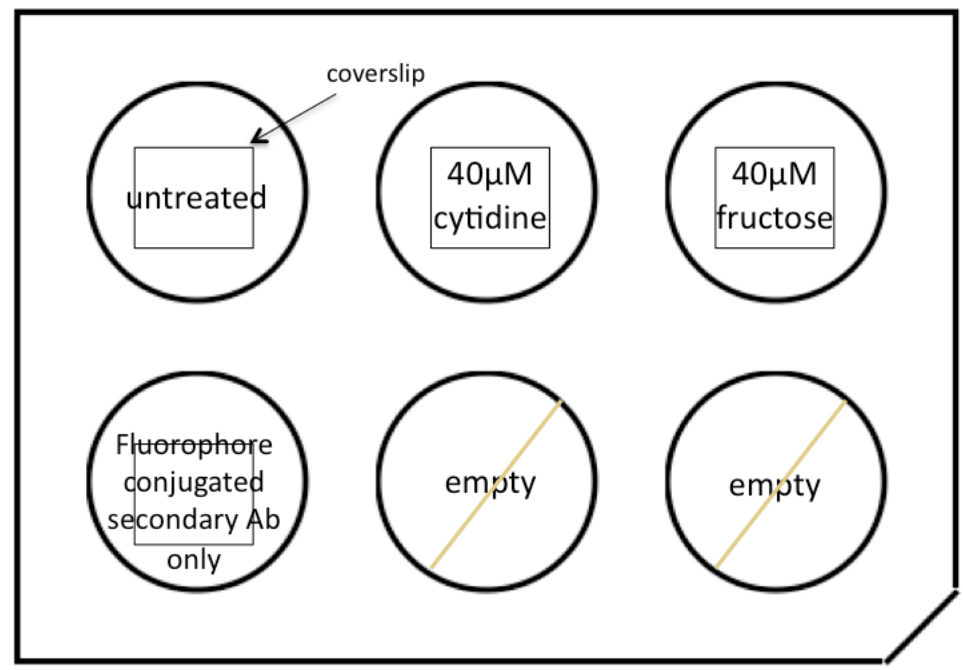

Figure 8: Experimental design for 6-well plates used to grow and treat cells for the microscopy based endocytosis assay. 


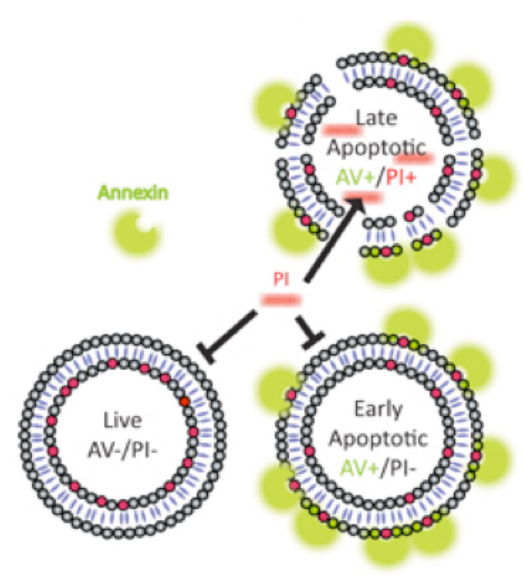

Figure 9: Annexin V (AV) and propidium iodide (PI) staining can be used to detect the apoptotic status of cells (figure adopted from http://www.stmichaelshospital.com/research/facilities/flowcytometry-viability-apoptosis.php).

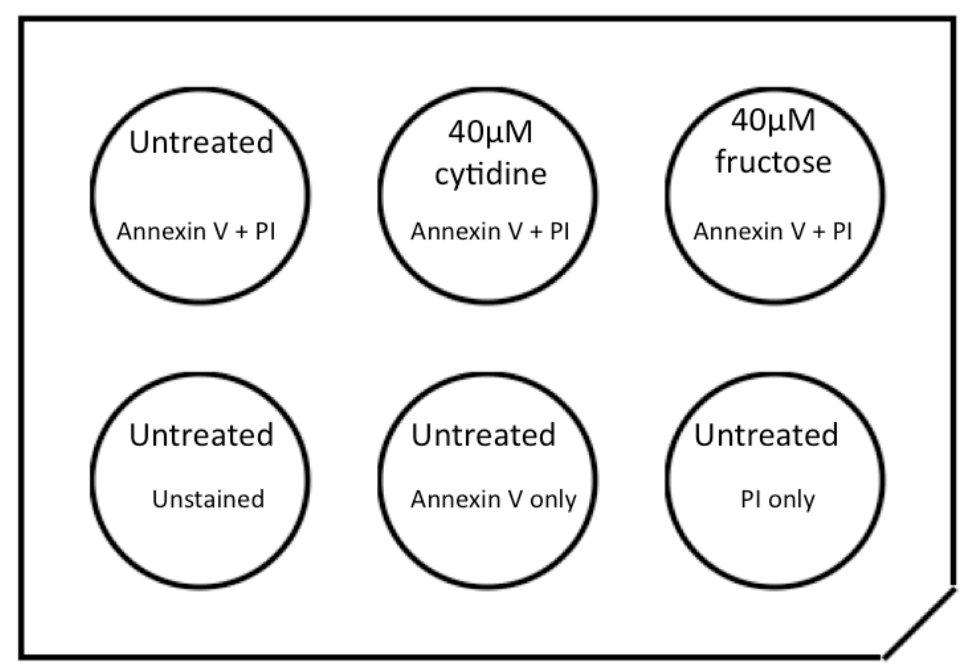

Figure 10: Experimental design for 6-well plates used to grow, treat and stain cells for the flow cytometry based cell viability assay. 


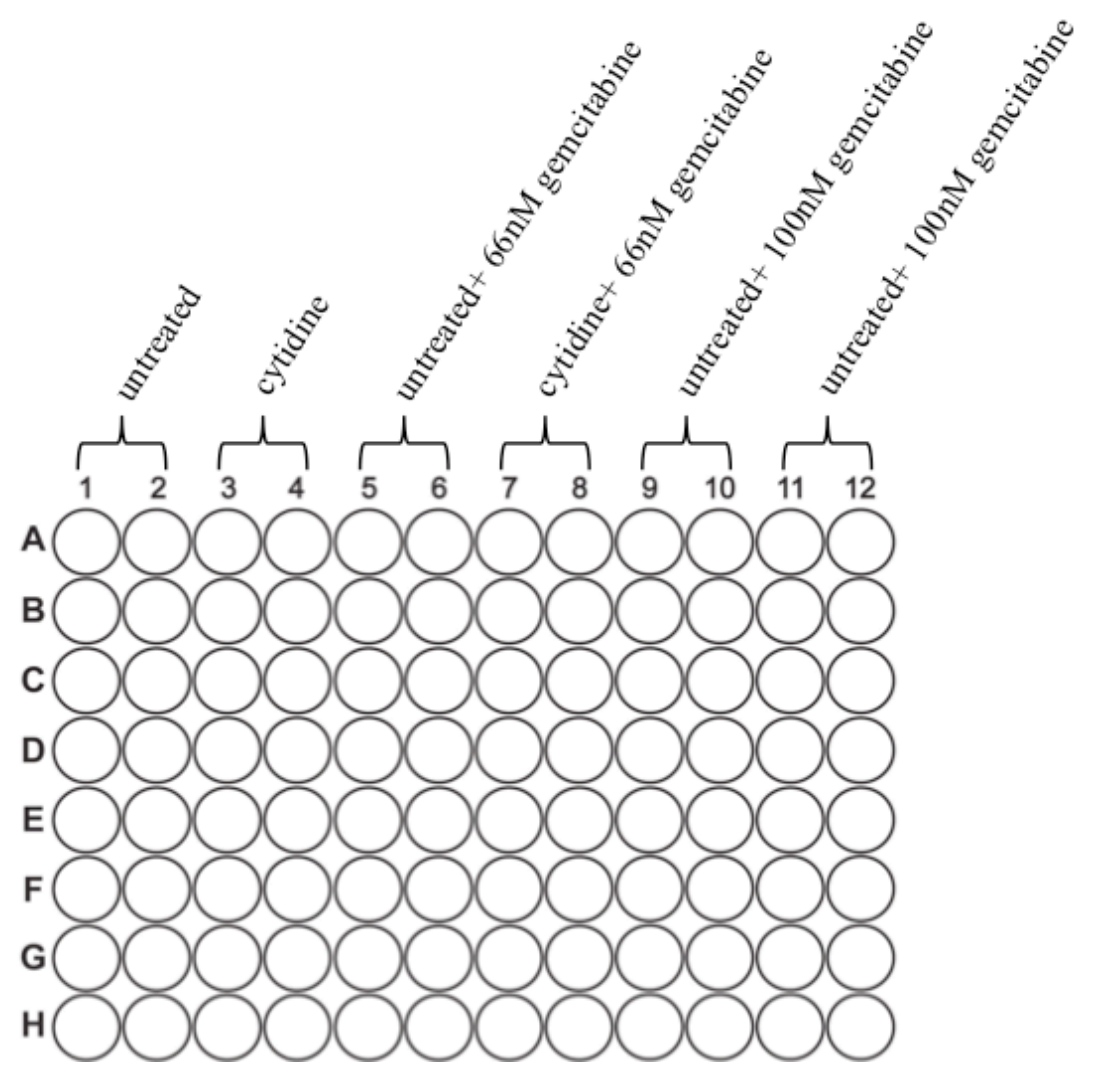

Figure 11: Treatment layout for MTT assays. 


\section{RESULTS}

\section{Cytidine exposure leads to a decrease in surface fluorescence from HA-hENT1}

To confirm substrate dependent internalization of hENT1, surface fluorescence from HAhENT1 was measured via flow cytometry since this is a highly sensitive technique that allows a precise and quantitative measure of fluorescence. To account for day-to-day variations in transfection efficiencies and cell count after sample preparation, surface fluorescence was normalized to the fructose control and compared to the untreated control to determine if the effects observed were statistically significant. Results from these analyses showed that cytidine treatment leads to a decrease in total surface fluorescence from HA-hENT1 compared to untreated, suggesting a decrease in PM HA-hENT1 (Figure 12).

\section{Cytidine is not cytotoxic under the conditions used}

Because the concentration of cytidine I used $(40 \mu \mathrm{M})$ was substantially higher than normal extracellular cytidine concentration $(0.6 \mu \mathrm{M})$, I confirmed that this concentration is not toxic to cells since this would mask the effect of cytidine treatment. I performed a flow cytometry based cell viability assay on cells that were treated in the presence and absence of cytidine. Annexin V and PI labeling was used to distinguish between cells undergoing early and late apoptosis. My analyses confirmed that cytidine is not cytotoxic under the conditions used (Figure 13).

\section{Cytidine exposure leads to the formation of intracellular punctate structures}

Preliminary findings suggested that hENT1 was internalized on extended exposure to substrate. To visually confirm redistribution of hENT1 after cytidine treatment, cells transfected with HA-hENT1 and exposed to cytidine were analyzed by confocal microscopy. However, I noted that different transfection reagents led to different cellular responses in terms of growth 
behavior and viability. Therefore, in order to achieve good transfection efficiency without altering the growth behavior of cells or decreasing viability, I first optimized the transfection conditions of four different transfection reagents (Figure 14). Lipofectamine 3000 was chosen as the transfecting reagent because, compared to other reagents, it showed the highest transfection efficiency without being cytotoxic or changing the growth behavior of cells compared to untransfected cells (Figure 14). Although Lipofectamine 2000 and Polyjet have been previously used in our lab with good transfection efficiencies, Lipofectamine 2000 is relatively cytotoxic (compared to Lipofectamine 3000) to HEK cells while Polyjet is cytotoxic and leads to cells growing in clumps after transfection (Figure 14A). Both of these characteristics are unfavourable, especially for microscopy because 1) cells need to be seeded at a low density so they grow in a uniform monolayer and 2) transfecting cells at a low density is not practical when using a "harsh" transfecting reagent. Based on these findings, Lipofectamine 3000 was used as the transfection reagents for all experiments requiring transfection.

To visually confirm redistribution of hENT1 after cytidine treatment, cells transfected with HA-hENT1 were analyzed by confocal microscopy. When analyzing micrographs from endocytosis assays of membrane proteins, it is important to be able to confidently interpret the identity of intracellular structures. This could be problematic when working with a protein fused to a fluorescent protein or fluorophore because there is no way to differentiate between protein that was internalized and newly synthesized protein that is being trafficked to the PM. In such cases, there is also no way to be sure whether peri-nuclear localization shows nascent protein being processed in the ER or internalized protein being recycled in the trans-Golgi network. Therefore, I decided to label only the PM population of the target protein and then follow its localization. In this way, I could conclude that all intracellular signal I observe is due to 
internalization of protein that was once at the PM. To do this, I incubated cells with an anti-HA antibody prior to cytidine treatment, which would interact with the extracellular epitope of the PM-located transiently expressed HA-hENT1 protein. The resultant micrographs show exclusive PM localization of hENT1 in untreated (no cytidine) cells (Figure 15, Panel 1), which persists after 30 minutes of cytidine treatment (Figure 15, Panel 2). However, intracellular punctate structures start to appear after 4 hours of cytidine treatment (Figure 15, Panel 3) and numerous punctate structures were observed after 6 hours (Figure 15, Panel 4). Cytidine treated cells that did not show evidence of intracellular punctate structures (especially after 6 hours) appeared to have sections of the PM that were devoid of HA-hENT1 (Figure 15, arrows). Figure 15B suggests that some of these devoid sections (yellow arrows) were small because they don't appear throughout the $\mathrm{Z}$ series. Overall, 6 hours of cytidine treatment shows an increase in intracellular punctate structures as well as a decrease in surface fluorescence from HA-hENT1.

\section{Cytidine exposure results in decreased NBTI binding}

FACS and microscopy analyses suggested that hENT1 is redistributed away from the membrane on repeated exposure to substrate. However these assays were done with transiently over-expressed proteins, which may not behave equivalently to endogenous protein. To confirm that my observations were consistent with the behavior of endogenous hENT1, I used NBTI, which is a high-affinity $(0.377 \mathrm{nM})$, tight-binding, non-transported nucleoside analog, to "label" endogenous ENT1 proteins in cells. The concentration of NBTI used in these experiments is in the nM range, (NBTI selectively binds to ENT1 when present in the nM range) it can be concluded that the binding sites represent hENT1 only and no other ENT isoform. If cytidine treatment leads to hENT1 re-distribution away from the plasma membrane without being replaced by newly synthesized or trafficked hENT1, then we would expect to see an overall 
decrease in the number of NBTI binding sites. I measured a small decrease in bound NBTI upon cytidine pre-treatment which suggested that there might be a decrease in the number of hENT1 binding sites, following prolonged exposure to cytidine ( $\mathrm{B}_{\max }$ untreated $0.445 \pm 0.184905381$ $\mathrm{pmol} / \mathrm{mg}$ protein compared to cytidine treated $0.37 \pm 0.147783626 \mathrm{pmoles} / \mathrm{mg}$ protein) (Figure 16A). Since these data did not support the prediction, I transformed them into Scatchard plots, which present the ratio between bound and free NBTI (y-axis) as a function of bound NBTI ( $\mathrm{x}$ axis). Systems that have a single type of binding site appear as a straight line when converted into Scatchard plots and those with two types of binding sites appear as a curvilinear plot (Rosenthal, 1967). Scatchard plot analysis of my data suggested that untreated HEK293 cells have two types of NBTI binding sites, (Figure 16B), possibly representing two populations of hENT1 proteins, one of which is redistributed away from the membrane after cytidine treatment (Figure 16C), since the post-treatment data suggest a single binding site.

\section{hENT1-dependent substrate uptake does not decrease with prior exposure to cytidine}

Since my previous data suggested that hENT1 protein levels decrease following cytidine treatment, I predicted that this decrease would be accompanied by a decrease in substrate transport. However, surprisingly, there was no difference in substrate uptake in cells treated with cytidine compared to the control (Figure 17A). These assays were conducted in $\mathrm{Na}^{+}$free buffer meaning that only ENT-dependent uptake is being measured. One interpretation of these data is that the concentration of 2-chloroadenosine $(10 \mu \mathrm{M})$ is in the linear range of uptake for untreated cells (Figure 17A), but is possibly a saturating concentration in cytidine treated cells because they have less hENT1 at the PM. I tested this by conducting assays with lower concentrations of 2-chloroadenosine $(5 \mu \mathrm{M})$ and found no difference in uptake between cytidine treated and untreated cells (Figure 17B). 
ENT1 and ENT2 are the only isoforms thought to be present at the PM and capable of transporting 2-ChAdo. To determine whether hENT2 was compensating for the potential redistribution of hENT1 away from the membrane, resulting in an overall unchanged substrate uptake, transport of $\left[{ }^{3} \mathrm{H}\right]$ hypoxanthine, which requires ENT2 for uptake, was measured following pre-treatment with cytidine. My data show no difference between the control and cytidine treated cells (Figure 18), suggesting that ENT1 internalization is not compensated for by an increased ENT2-mediated uptake. To confirm that hypoxanthine uptake is exclusively hENT2 mediated, uptake was measured after a short (12 minute) NBTI inhibition of hENT1-mediated uptake, which will allow for the measurement of ENT2-mediated hypoxanthine uptake only. The results (Figure 19) show almost identical uptake compared in the presence or absence of NBTI confirming that hypoxanthine uptake is exclusively hENT2 mediated and supporting the results seen in Figure 18. Taken together, these results showed that cytidine treatment does not change overall substrate uptake and that hENT2 is not compensating for the lost hENT1.

\section{Cytidine exposure leads to altered transport kinetics of hENT1}

Based on my data showing a decrease in PM hENT1 protein levels but no change in nucleoside transport, I performed kinetic assays to understand the mechanism underlying this regulation. These assays showed an increase in $\mathrm{V}_{\max }\left(\mathrm{V}_{\max }\right.$ untreated $464.25 \pm 94.2 \mathrm{pmoles} / \mathrm{mg}$ protein/s compared to $\mathrm{V}_{\max }$ cytidine $725 \pm 144.5 \mathrm{pmoles} / \mathrm{mg}$ protein/s, mean $\pm \mathrm{SEM}, \mathrm{n}=3$ )(Figure 20A) and $K_{m}\left(K_{m}\right.$ untreated $337.7 \pm 30.6 \mu \mathrm{M}$ compared to $K_{m}$ cytidine $462.3 \pm 36.7 \mu \mathrm{M}$, mean \pm SEM, $n=3$ )(Figure 20B) after cytidine treatment. This means that, after cytidine treatment, the remaining hENT1 at the PM have a higher rate of uptake, such that the overall substrate transport is the same as that of untreated cells. 


\section{Cytidine pre-treatment results in an increased cytotoxicity from gemcitabine}

Based on my data so far, I predicted that cytidine pre-treatment would have no effect on gemcitabine cytotoxicity. To confirm this, MTT assays were performed with the pancreatic cancer line, $\mathrm{BxPC} 3$, because gemcitabine is used as the first line treatment for pancreatic cancer and this cell line serves as a physiologically relevant model. For these assays, the gemcitabine concentrations used were 66 and $100 \mathrm{nM}$. The results were unexpected since they showed that pretreatment with cytidine leads to a higher cytotoxicity from gemcitabine when compared to cells treated with gemcitabine alone (Figure 21). This effect was consistent when using a low gemcitabine concentration $(66 \mathrm{nM})$ as well a higher concentration $(100 \mathrm{nM})$. But, while cytidine pre-treatment followed by $66 \mathrm{nM}$ gemcitabine showed a synergistic effect, cytidine pre-treatment followed by $100 \mathrm{nM}$ gemcitabine showed an additive effect. 
A.
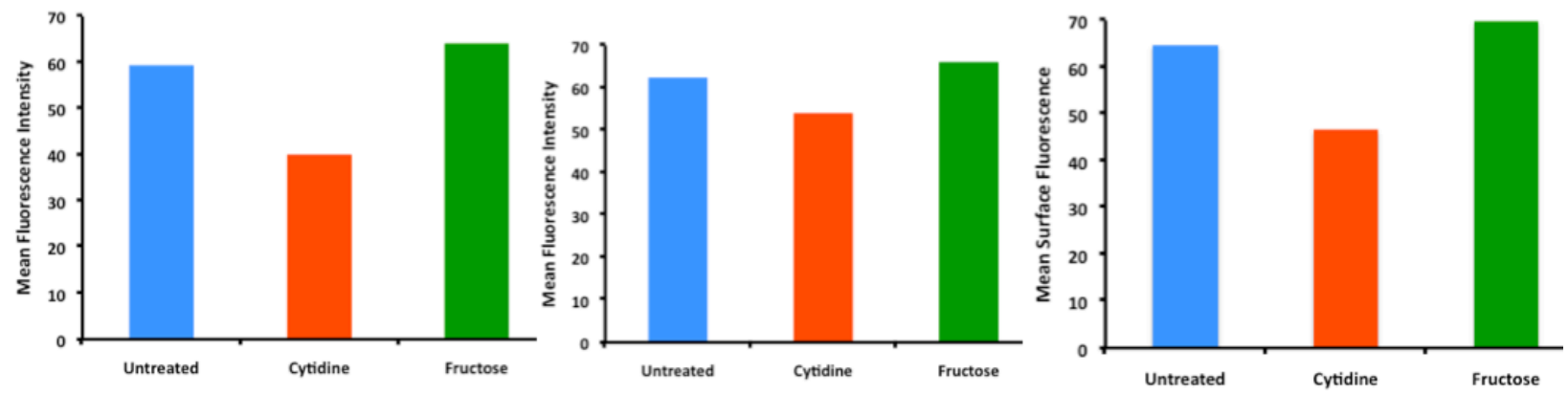

B.

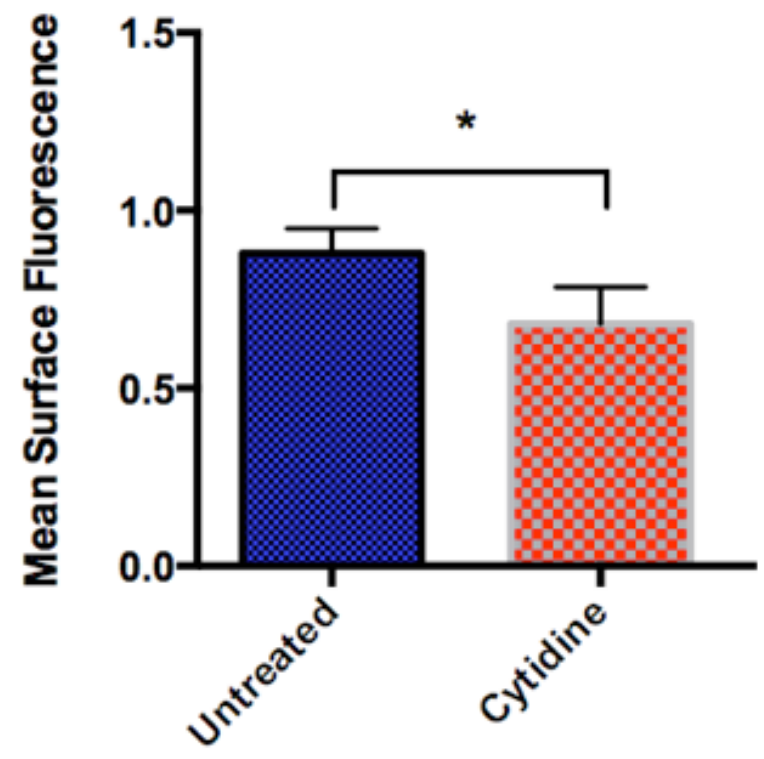

Figure 12: Surface level of HA-ENT1 decreases following treatment with cytidine. Cells expressing HA-hENT1 were treated in the presence or absence (untreated) of specific substrate (cytidine or fructose; $40 \mu \mathrm{M}, 6$ hours) and surface presence of HA-hENT1 was analyzed using FACS. Three individual experiments (A) were normalized to the fructose control to account for variations in transfection efficiencies and cell count. B) Pooled data from the three individual experiments in (A), normalized to fructose condition, mean $+/$ - SEM, $n=3$, student's t-test used to determine statistically significant differences between untreated and cytidine treated cells $(\mathrm{p}<0.05)$. 


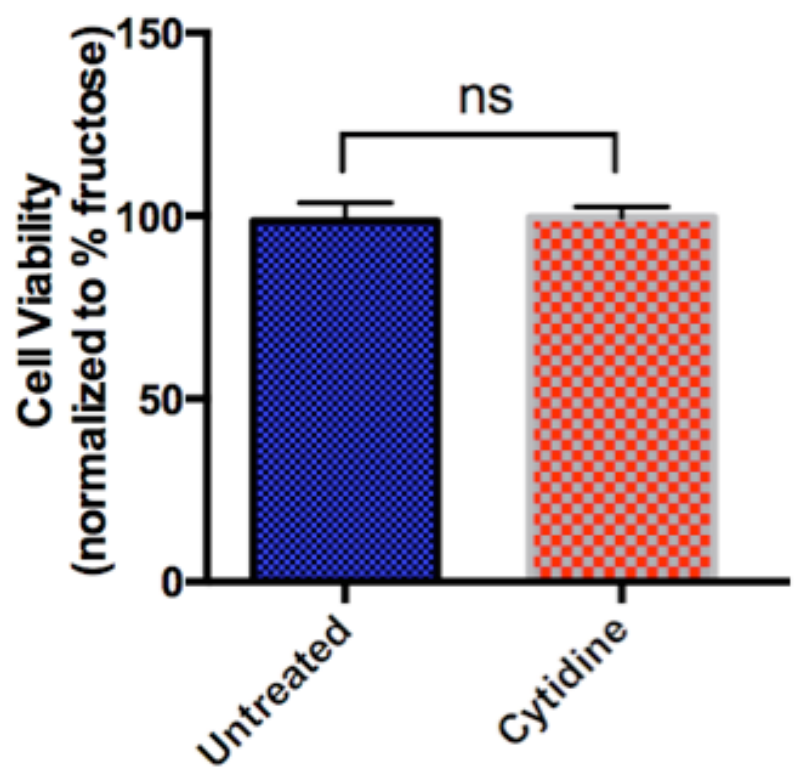

Figure 13: Cytidine is not cytotoxic under the conditions used. Treatment of HEK293 cells with cytidine $(40 \mu \mathrm{M}, 6 \mathrm{hrs})$ does not lead to any decrease in cell viability based on Annexin V and PI staining post-treatment. Figure shows pooled data, normalized to fructose condition, mean +/SEM, $n=3$, student's t-test used to determine statistically non-significant differences between untreated and cytidine treated. 
PolyJet
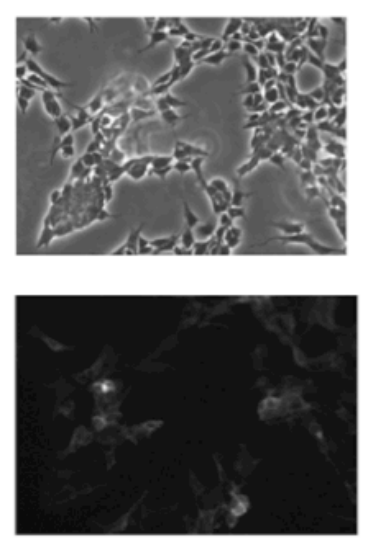

Lipocalyx Viromers
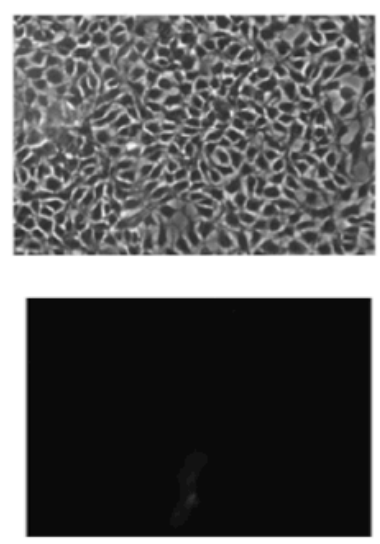

Lipofectamine 2000
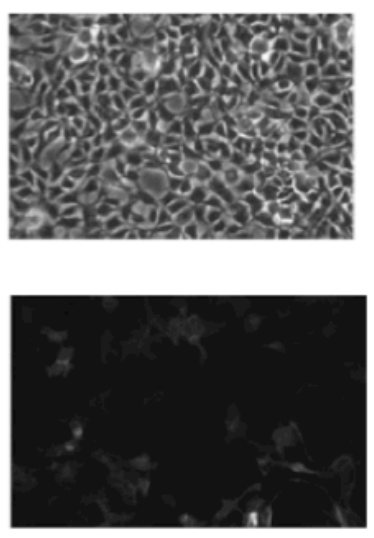

Lipofectamine 3000
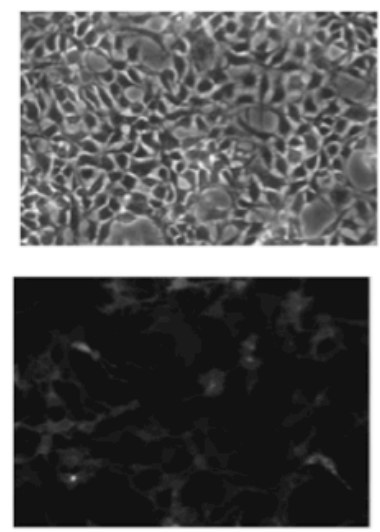

Figure 14: Effects of various transfection reagents on HEK cells. PolyJet, Lipocalyx Viromers RED, Lipofectamine 2000 and Lipofectamine 3000 were used to transfect HEK cells with GFP empty vector. The images, shown in bright field (A) and under fluorescence (B), were taken 24 hours after transfecting with optimized amounts of DNA and reagent. Optimization was performed by using combinations of either half the volume (0.5) of DNA/reagent suggested in the manufacturer's protocol or the exact volume suggested (1). The optimal conditions were PolyJet (1reagent:0.5 DNA), Lipocalyx Viromers (50uL reagent:1DNA), Lipofectamine 2000 (1reagent:1DNA) and Lipofectamine 3000 (1 reagent:0.5DNA). 
A.

1) Untreated
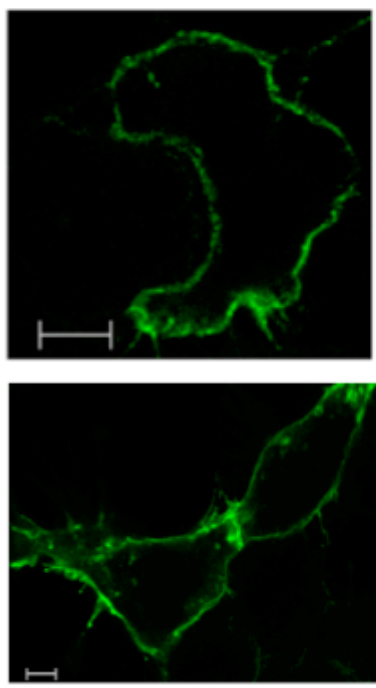

2) 30 min cytidine
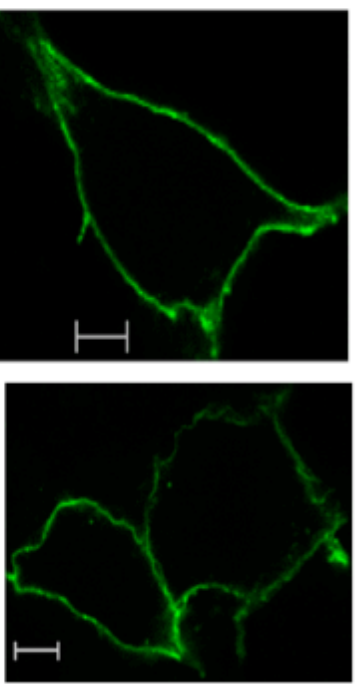

3) 4 hrs cytidine
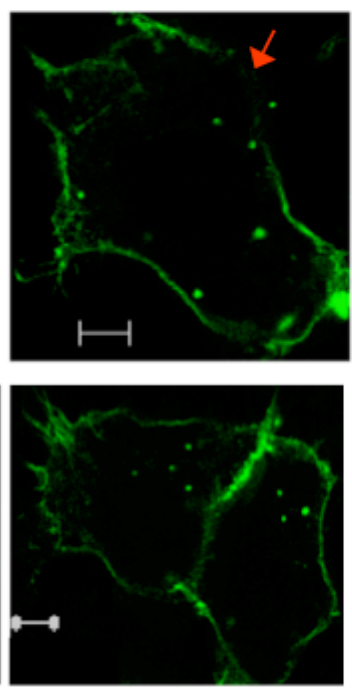

4) 6 hrs cytidine
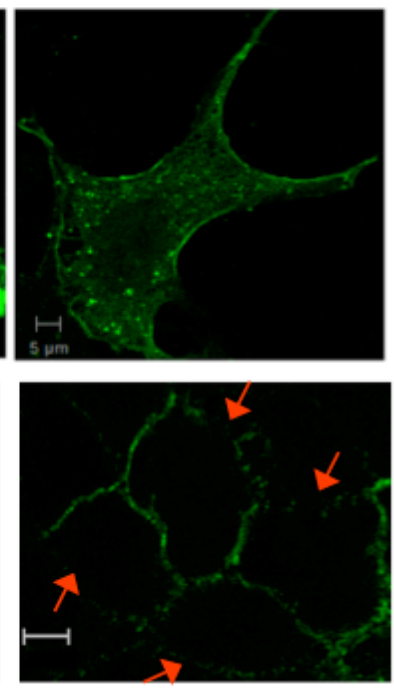

B.
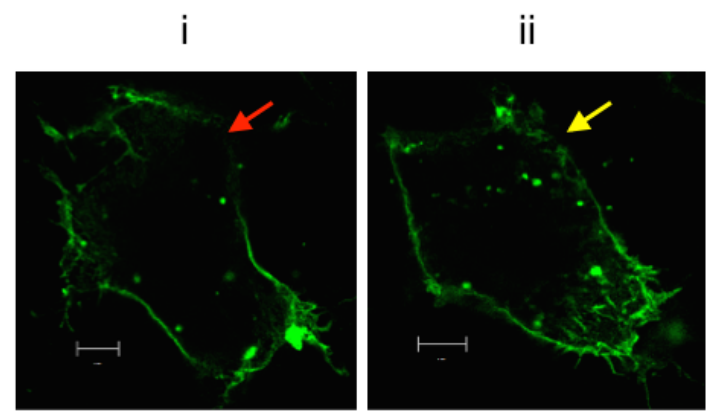

iii

iv
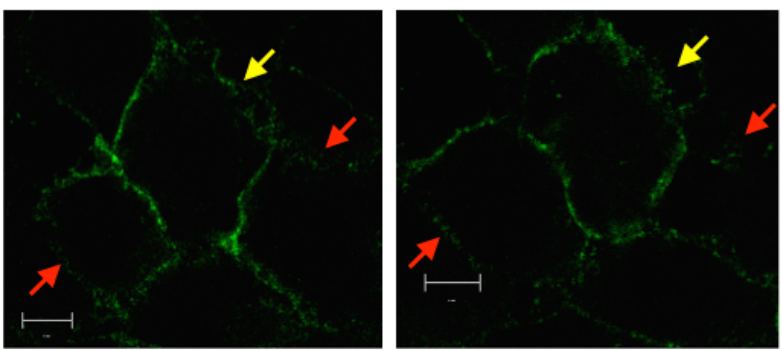

Figure 15: Cytidine treatment leads to the formation of intracellular punctate structures. A) Confocal microscopy of cytidine treated HEK293 cells showed numerous intracellular punctate structures and PM regions that had lost HA-hENT1 labeling (red arrows). Each micrograph shows the middle section of a $\mathrm{Z}$ series. $\mathrm{B}$ ) Top ( $\mathrm{i}$ and iii) and bottom (ii and iv) sections of the $\mathrm{Z}$ series for 4 and 6 hour conditions shown in A. Red arrows point to the regions that remain devoid of HA-hENT1 compared to the middle section shown in A. Yellow arrows point to the regions that show HA-hENT1 presence compared to the middle stack shown in A. This figure shows representative micrographs collected from three individual experiments (6-7 fields of view per experiment). Scale bars $=5 \mu \mathrm{m}$. 
A.

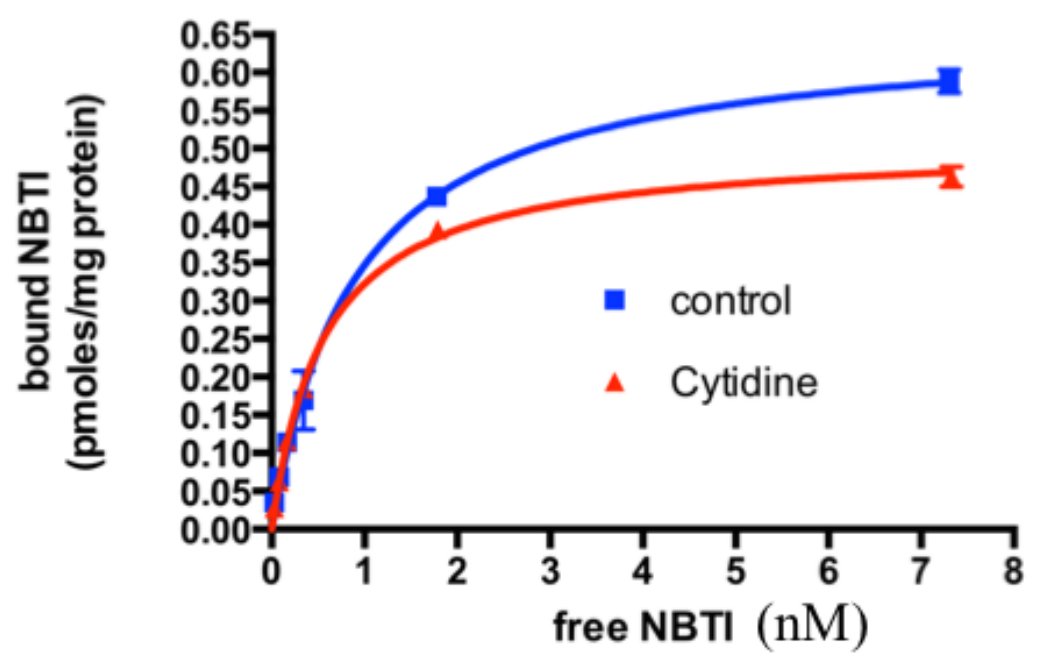

B.

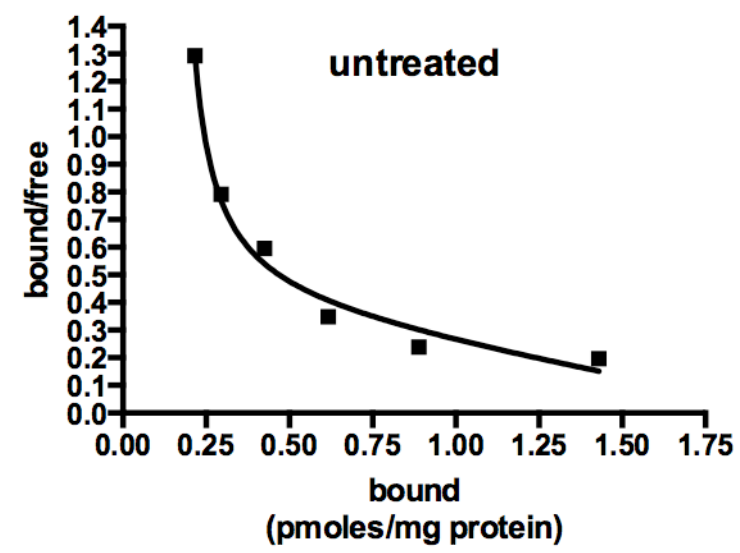

C.

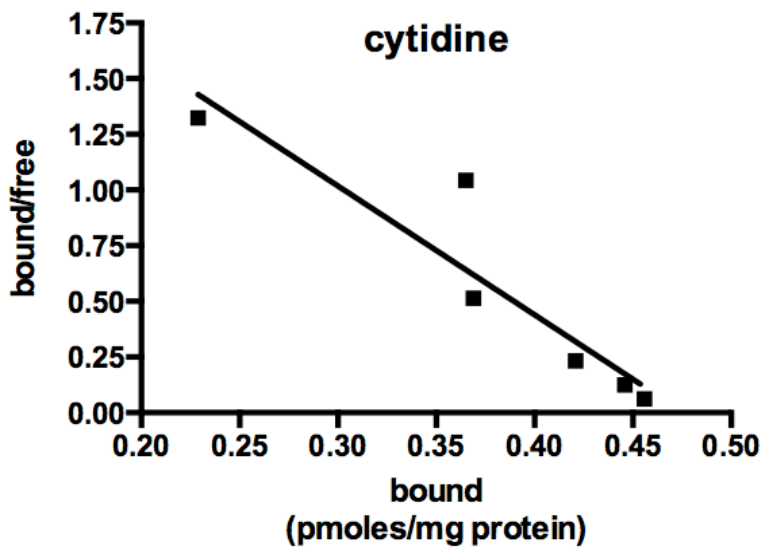

Figure 16: HEK cells lose one of two NBTI binding sites following exposure to cytidine. (A) Cells were treated in the presence or absence of cytidine ( $40 \mu \mathrm{M}, 6 \mathrm{hr})$ prior to the NBTI binding analyses, which show a decrease in bound NBTI after cytidine treatment. Data presented as Scatchard plots show a curvilinear profile for untreated cells (B), representing more than one type of binding site. Following treatment with cytidine $(\mathrm{C})$, only one binding site appears to be present, as suggested by the linear Scatchard plot. Figures show representative experiments (done in duplicates, $\pm \mathrm{SD}$ ), experiment was repeated three times with similar results. 
A.

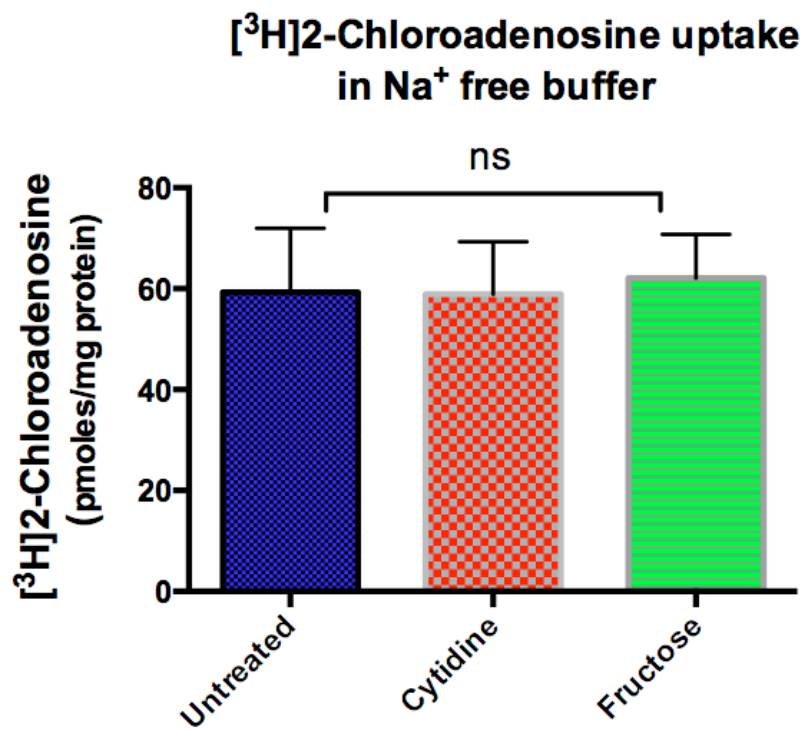

B.

\section{$\left[{ }^{3} \mathrm{H}\right] 2$-chloroadenosine uptake} in $\mathrm{Na}^{+}$free buffer

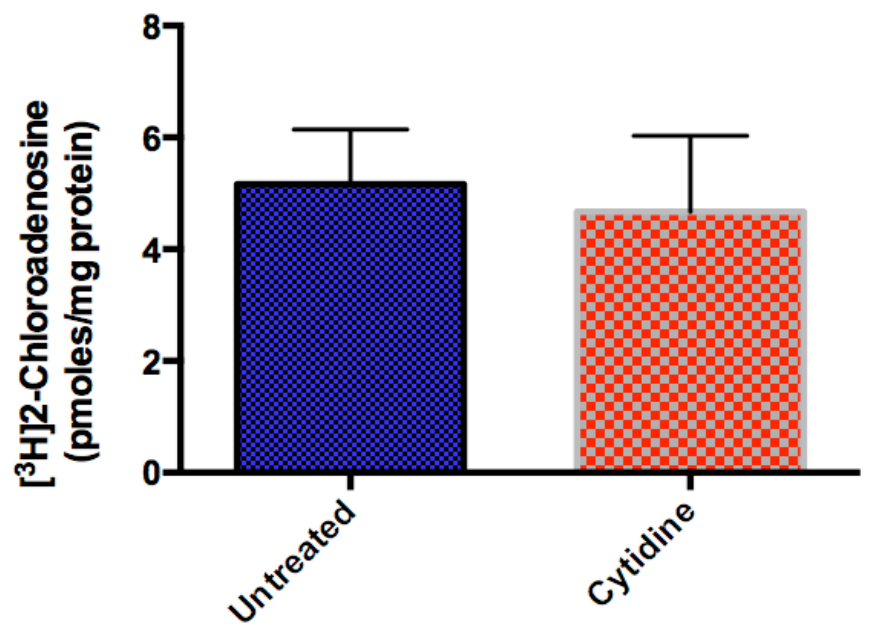

Figure 17: Cytidine exposure has no effect on subsequent hENT1-mediated nucleoside transport. HEK293 cells treated in the presence of cytidine $(40 \mu \mathrm{M}, 6$ hours $)$ showed no difference in the uptake of $10 \mu \mathrm{M}(\mathrm{A})$ or $5 \mu \mathrm{M}(\mathrm{B})\left[{ }^{3} \mathrm{H}\right] 2$-chloroadenosine compared to untreated cells. A) Figure shows pooled data, mean $+/-$ SEM, $n=3$, One-Way ANOVA used to determine statistically non-significant differences between untreated, cytidine and fructose treated cells. B) Figure shows pooled data, mean $+/-\mathrm{SD}, \mathrm{n}=2$. 


\section{$\left[{ }^{3} \mathrm{H}\right]$ Hypoxanthine uptake in $\mathrm{Na}^{+}$free buffer}

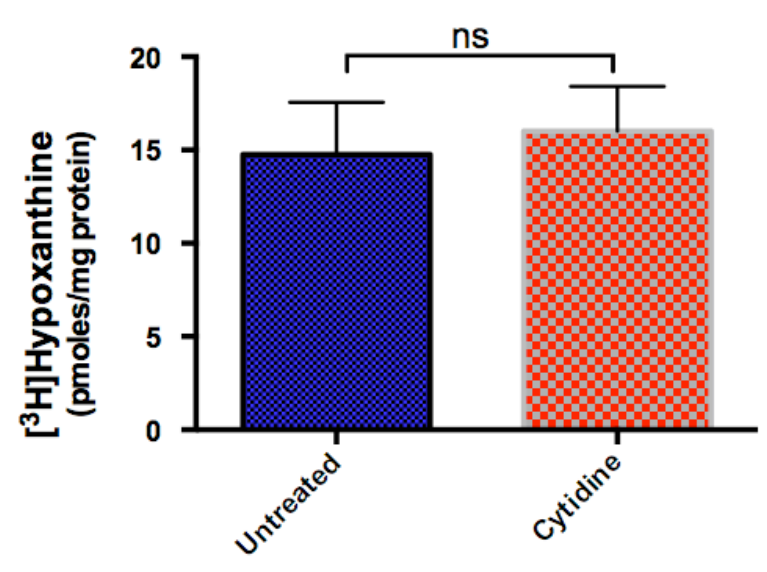

Figure 18: The redistribution of hENT1 away from the plasma membrane is not compensated for by an increased hENT2 activity. HEK293 cells treated in the presence or absence of cytidine $\left(40 \mu \mathrm{M}, 6\right.$ hours) showed no difference in subsequent uptake of $\left[{ }^{3} \mathrm{H}\right]$ hypoxanthine. Figure shows pooled data, mean $+/$ - SEM, $n=3$, student's t-test used to determine statistically non-significant differences between untreated and cytidine treated cells. 


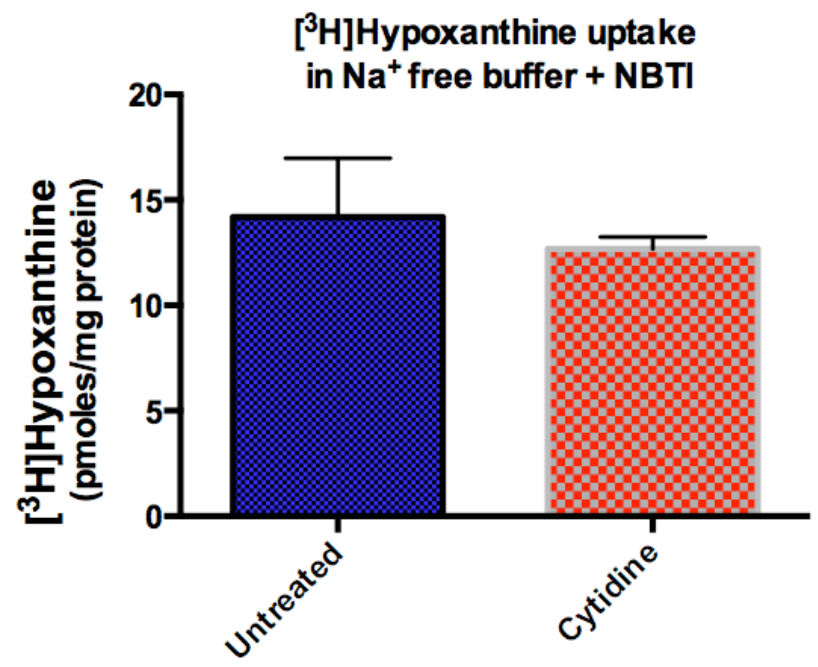

Figure 19: Hypoxanthine uptake is hENT2 mediated. HEK 293 cells treated in the presence or absence of cytidine $(40 \mu \mathrm{M}, 6$ hours) show no difference in NBTI $(500 \mathrm{nM})$ inhibited hypoxanthine uptake $(10 \mu \mathrm{M})$. Figure shows representative experiment conducted in sexuplicate, mean $+/$ - SD. Experiment repeated twice with similar results.

A.

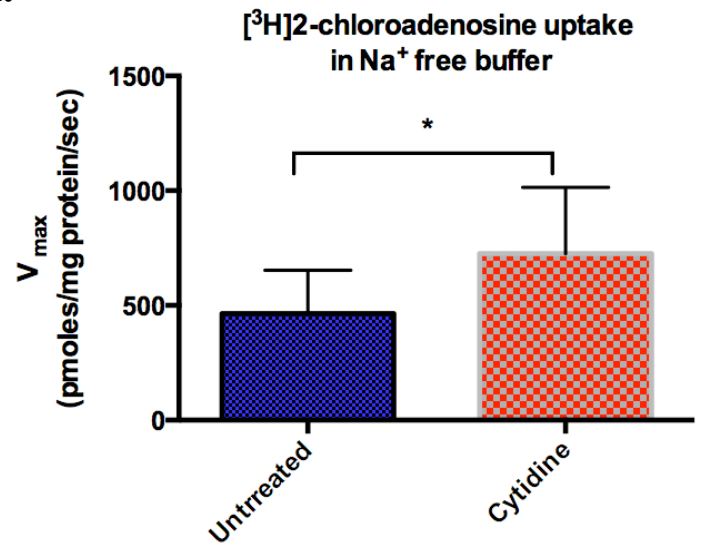

B.

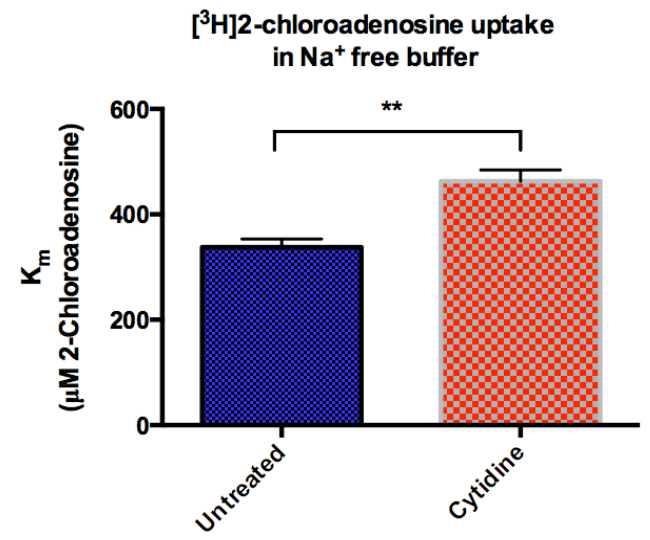

Figure 20: Cytidine treatment leads to an increase in hENT1 mediated uptake rate (A) and decreased transporter affinity for substrate (B). Transport assays done with increasing 2chloroadenosine concentrations $(5,10,50,100,250$, and $500 \mu \mathrm{M})$ showed that cytidine treatment results in an increased $V_{\max }$ and $\mathrm{K}_{\mathrm{m}}$. Figure shows pooled data, mean $+/$ - SEM, $\mathrm{n}=3$, student's ttest used to determine statistically significant differences between untreated and cytidine treated cells. 


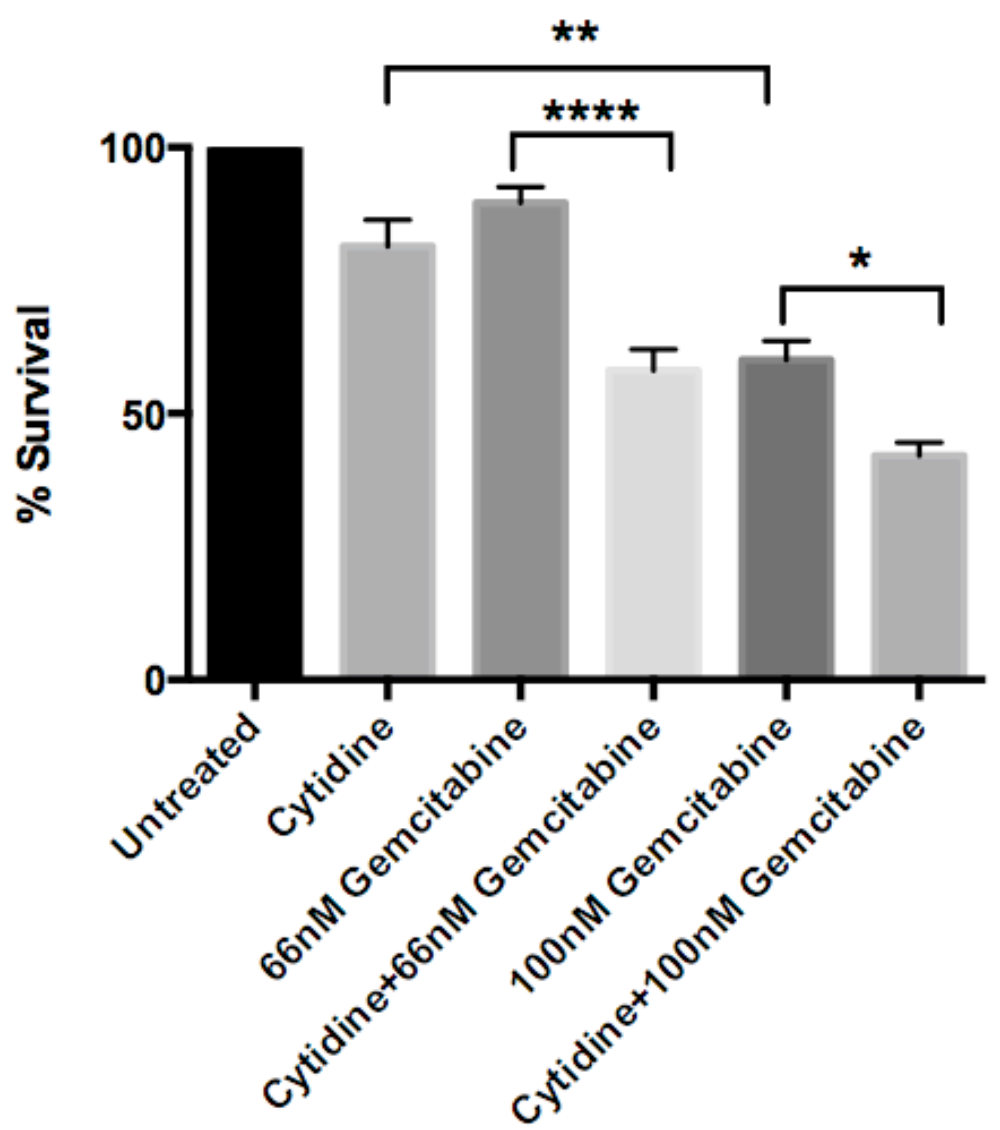

Figure 21: Cytidine pre-treatment leads to an increased cytotoxicity from gemcitabine in BxPC3 cells. Cells treated in the presence of cytidine $(40 \mu \mathrm{M}, 6$ hours) prior to gemcitabine treatment (48 hours) show reduced viability, measured as a decrease in the absorbance from MTT at 550nm. Figure shows pooled data, mean +/- SEM, n=3, one-way ANOVA with Newman-Keuls multiple comparisons test used to determine statistically significant differences. 


\section{Discussion}

\section{Substrate-dependent regulation of hENT1}

hENT1 is among the transporters that mediate the first step of nucleoside salvage and regulate the supply of nucleosides throughout the life cycle of a cell, but we only have a limited knowledge of its regulatory mechanisms. Endocytosis and recycling is a mechanism that maintains functional hENT1 and their abundance at the PM (Nivillac et al, 2011; Torres et al, 1992). hENT1 undergoes continuous recycling (via clathrin-mediated endocytosis) and degradation (in lysosomes) (Nivillac et al, 2011). Because recycling is important in the life of hENT1 and other membrane proteins such as the Tf and LDL receptors, it is possible that this process is used as a mechanism to regulate the response to cellular needs. Based on this and the evidence for substrate dependent regulation of other transport proteins, the aim of this study was to investigate the substrate-dependent regulation of hENT1. It was hypothesized that prolonged exposure to a bolus concentration of nucleosides leads to the redistribution of hENT1 away from the plasma membrane, which will lead to a decreased efficacy of gemcitabine.

Direct substrate-dependent regulation has been reported for other transporters localized at the plasma membrane (Seron et al, 1999; Hou et al, 2009; Saunders et al, 2000), but has not been shown to occur for SLC28 or SLC29 nucleoside transporters. It is known that adenosine binds to purinergic receptors (such as A1) and triggers purinergic signaling, which regulates hENT1 expression and function (Hughes et al, 2015). However, the direct effects of a bolus concentration of nucleoside on hENT1 presence at the PM and function have never been reported. My data show that a bolus concentration of substrate negatively regulates hENT1 abundance at the plasma membrane and supports the hypothesis that persistent presence of substrate results in enhanced internalization of transporters. These data are also similar to those 
reported for other transporters. For example, substrate dependent down regulation of the yeast uracil permease, Fur4, and the glucose transporter, GLUT2, has been reported (Seron et al, 1999; Hou et al, 2009). When the intracellular concentration of uracil increases beyond the capacity of the cell to metabolize it effectively, Fur4 is endocytosed and degraded in a ubiquitin dependent fashion (Seron et al, 1999). Similarly, under high glucose conditions GLUT2 is internalized and degraded in the lysosomes (Hou et al, 2009). Yet another example is the human dopamine transporter (hDAT), which undergoes endocytosis upon treatment with amphetamine (a substrate for DAT) (Saunders et al, 2000).

My finding that hENT1 is internalized on prolonged exposure to substrate is consistent with previous data for endogenously expressed ENT1 in chromaffin cells (Torres et al, 1992). Torres et al (1992) showed that two hours after covalently attaching NBTI to ENT1, the NBTIENT1 complex was endocytosed and degraded. While this study used covalently bound, radiolabelled NBTI as a marker of ENT1 to investigate the transporter's recycling, it also suggested that substrate binding induces ENT1 internalization. Therefore, whether their results truly represent ENT1 recycling or a substrate-dependent regulation is unclear. It was also unclear whether the same effect would be seen in response to a natural substrate without any chemical cross-linking to the transporter. My results show that a natural substrate (i.e cytidine) also induces a similar response but contrasts with previous findings in that cross-linked NBTI induced ENT1 internalization after 2 hours while cytidine treatment led to ENT1 internalization after 6 hours. This difference in time could be due to the chemical crosslinking of the substrate to ENT1, which locks the transporter in one conformation and possibly targets for rapid degradation. My observation of a decrease in PM HA-hENT1 but no intracellular punctate structures in cytidine-treated cells, suggesting that a fraction of hENT1 is rapidly degraded upon 
internalization (discussed in following sections) is also similar to the results of Hou et al (2009) where micrographs show a decrease in PM fluorescence from GLUT2-Myc but no intracellular GLUT2-Myc (because internalized GLUT2 undergoes lysosomal degradation close to the PM).

Before this study, there have been no others that used HEK cells as a model for studying hENT1. Most data regarding ENT1 structure and function has been collected from Xenopus oocytes (Yao et al, 2011), mouse models (Rose et al, 2011; Rose et al, 2010), HL-1 cells (Chaudary et al, 2002; Chaudary et al, 2004), PK-15 cells (Robbilard et al, 2008; Bone et al, 2007), COS-7 cells (Chlorocebus aethiops, a.k.a African green monkey, kidney) (Reyes et al, 2011; Nivillac et al, 2011) and MCF-7 cells (Coe et al, 2002; Nivillac et al, 2011). Oocytes and PK-15 (porcine cell line) cells are often used for functional studies of specific ENT1 mutants because these are natural ENT1-null models. Mouse cell lines are more appropriate for studying mouse ENTs (mENTs) such as the murine cardiomyocytes, HL-1, which have been used to demonstrate the cardioprotective effects of adenosine under hypoxic conditions (Chaudary et al, 2004). Being a human cell line, MCF-7 (human breast adenocarcinoma) is more appropriate for studying hENT1 and has been used to show the life cycle of hENT1 by our group (Nivillac et al, 2011). However, MCF-7 cells can grow in clumps, which is not an ideal condition for microscopy analyses. The choice of HEK 293 was based on the criteria that 1) the cell line should be a good candidate for all or most of the required experiments and 2) endogenously express hENT1 with normal localization and function. HEK293 cells meet these criteria and have been successfully used in our lab for studying both endogenous and heterologously expressed hENT1 (unpublished data). Though HEK cells proved to be a good model for confirming substrate-dependent regulation of hENT1, they were not appropriate for the latter part of the project, which involved the measurement of gemcitabine cytotoxicity. Gemcitabine is 
used as the first line treatment for pancreatic cancer, thus HEK cells are not a physiologically relevant model. Consequently, BxPC3 were chosen for the cytotoxicity assays. BxPC3 are a representative model for primary human pancreatic cancer and tumorigenicity was proven by xenografts in nude mice (Tan et al, 1986). On the other hand, BxPC3 could not be used for other experiments because they are very much adherent compared to HEK 293 and grow in clumps like MCF-7, which is not good for microscopy analyses.

I have shown that HEK cells are a good model for studying hENT1 function. My data show that, like COS-7 and MCF-7 cells (Nivillac et al, 2011), HEK cells have normal PM localization of hENT1. hENT1 proteins expressed in HEK cells also display normal nucleoside transport and inhibitor binding (NBTI) characteristics and therefore, are a good model system for functional analyses of endogenously and heterologously expressed hENT1.That internalized membrane proteins appear as intracellular punctate structures in HEK cells is consistent with the results of Chuang et al (2004), showing endocytosis of mutant rhodopsin-arrestin complexes in HEK cells as punctate structures. Comparison of my microscopy results to those of Nivillac et al (2011) show that like COS-7 and MCF-7 cells, HEK cells are also capable of normal hENT1 internalization and recycling. However, compared to MCF-7 cells (Coe et al, 2002), HEK cells have fewer NBTI binding sites $(1.01 \pm 0.04 \mathrm{pmoles} / \mathrm{mg}$ protein in MCF-7 compared to 0.445 $\pm 0.18 \mathrm{pmol} / \mathrm{mg}$ protein in HEK cells).

My data show also that HEK293 cells have two types of NBTI binding sites, suggesting two types of hENT1 populations. This is consistent with previous data (Boumah et al, 1992) that pre-dates the cloning and identification of the molecular species responsible for NBTI binding. It was shown that while BeWo cells have two types of NBTI binding sites, HeLa cells only have one type (Boumah et al, 1992). Boumah et al were able to resolve their NBTI binding data 
(curvilinear plot) for BeWo cells into two straight lines, which showed that the larger of the two NBTI binding populations bound NBTI with a higher affinity and the smaller population bound NBTI with a lower affinity. However, I was unable to resolve the Scatchard plots for untreated cells into two straight lines because the number and range of $\left[{ }^{3} \mathrm{H}\right]$ NBTI concentrations used in this study were both smaller than those used by Boumah et al (six concentrations between $0.186 \mathrm{nM}-7.45 \mathrm{nM}$ vs. twelve concentrations between 1 and $25 \mathrm{nM}$ ), which led to ambiguous computational analyses. Although the binding data presented in this study are strong evidence for the presence of two types of NBTI binding sites in HEK cells, more assays need to be performed with a wider range of $\left[{ }^{3} \mathrm{H}\right] \mathrm{NBTI}$ concentrations to determine the binding parameters of the two binding sites. The presence of two sub-populations of hENT1 is also reflected in the findings of Coe et al (2002) and Hughes et al (2015). Coe et al showed that PMA (Phorbol-12-Myristate-13Acetate, an activator of PKC) activation of PKC increased ENT1-mediated nucleoside transport without changing the number of NBTI-binding sites (i.e ENT1 proteins) at the PM and the reason for this was proposed to be the presence of an "active" $h E N T 1$ population and another "inactive" population. It was speculated that PKC activation of the previously inactive ENT1 proteins led to an increase in ENT1-mediated substrate transport (Coe et al, 2002). Similarly, Hughes et al reported that while a phosphosite mutant of hENT1 (S281A) displayed less than $20 \%$ of NBTI binding relative to wild type (WT) hENT1, the $\mathrm{V}_{\max }$ of substrate uptake only varied by a factor of two between the two transporters; they also speculated the presence of more than one hENT1 populations.

After I had confirmed that a population of hENT1 is redistributed away from the membrane following exposure to substrate, I predicted there would be a concomitant decrease in subsequent substrate transport due to the loss of hENT1 from the PM. This prediction was based 
on the findings of Saunders et al (2000), which showed that AMPH (amphetamine, a DAT substrate) treatment resulted in a decrease in cell surface hDAT and subsequent dopamine uptake. However, in contrast, my transport and kinetic data suggested no change in substrate uptake and a change in hENT1 transport kinetics, which was surprising. These results suggest that presence or absence of hENT1 at the membrane does not correlate directly with uptake, which is in agreement with the previously mentioned results of Hughes et al (2015) (i.e decrease in hENT1 $\mathrm{V}_{\max }$ inconsistent with decrease in NBTI binding sites in phosphosite mutants). A possible reason for this could be the presence of transporters at the membrane that are nonfunctional. This speculation is consistent with the previously mentioned studies of Coe et al (2002), Hughes et al (2015). The study by Coe et al (2002) reported an increase in hENT1 affinity for substrate binding and as already mentioned, it was proposed that the increased uptake via hENT1 was due to an activation of a transporter population already present at the membrane. My speculation is also supported by a previous finding that NBTI-induced endocytosis and degradation of ENT1 occurs in two phases (Torres et al, 1992). Covalently bound NBTI resulted in a fast internalization of ENT1 (half-life 2.2 hours) and a slow internalization (half-life 61.4 hours), suggesting two kinds of ENT1 populations. Based on this evidence and my NBTI binding data which suggest two ENT1 populations in HEK cells, I propose that prolonged exposure to substrate clears away the excess "inactive" hENT1 population and the remaining transporters at the PM display a different kinetic profile.

The change in kinetic parameters of hENT1 is consistent with my proposed model. Since the putative inactive population is still capable of binding NBTI (as suggested by the higher NBTI binding in untreated cells compared to cytidine), it is possible that substrates would engage with these inactive sites but would not be translocated, resulting in a decreased $\mathrm{V}_{\max }$ 
compared to cytidine treated cells which have only the active population and all binding substrates would get translocated. Finally, the increase in transport rate and decrease in transporter affinity that I observed here for hENT1 seems counter intuitive but is consistent with observations of other transporters. GLUT2 has a lower affinity of transport for glucose compared to GLUT1 but transports glucose at a faster rate (i.e, high $\mathrm{V}_{\max }$ and $\mathrm{K}_{\mathrm{m}}$ compared to GLUT1. Katagiri et al, 1992). Engineering a chimeric GLUT1 with a C terminal domain from GLUT2's resulted in a transporter with the higher $\mathrm{V}_{\max }$ and $\mathrm{K}_{\mathrm{m}}$ (lower affinity) of GLUT2.

Finally, while it is unknown how the two putative ENT1sub-populations differ and what makes one more prone to internalization, I speculate that it may be related to their oligomerization state. Since there are no reported splice variants of hENT1, one difference between the two hENT1 sub-populations could be a post-translational modification. Radiation inactivation experiments used to determine the molecular weight of ENT1 (Jarvis et al, 1986) suggested that ENT1 exists in the plasma membrane as dimers. Another report also suggested the existence of hENT1 dimers based on electrophorectic patterns (Torres et al, 1992) and our lab also has evidence of hENT1 homo and hetero oligomers based on co-immunoprecipitation and MYTH assays (Boladeras et al, unpublished data). Based on these previous findings, it is possible that the kind of oligomers that an ENT1 population forms, such as homodimer vs. heterodimer (with ENT2) or dimer vs. trimer etc., makes them more likely to be regulated by endocytosis.

\section{The effect of cytidine pre-treatment on gemcitabine efficacy}

Gemcitabine is used as the first line treatment for pancreatic adenocarcinoma. The presence of hENT1 on the PM of tumor cells is sufficient and necessary for the effective uptake of gemcitabine (Mackey et al, 1998). The enzymes involved in the pharmacokinetics of 
gemcitabine work together to produce the cytotoxic effect. Assuming my hypothesis was correct and prolonged exposure to substrate would lead to internalization and removal of hENT1 from the PM, I predicted that pre-treatment of cells with substrate would lead to a decreased efficacy of NA drug as a consequence of the internalization of ENT1. In order to test this, I used gemcitabine, which is an analog of cytidine, and a physiologically relevant cell line, as a model of the target tissue for use of this drug. But since my earlier findings suggested that cytidine pretreatment was not accompanied by a change in substrate uptake, I expected that there would be no change in gemcitabine cytotoxicity and it was therefore surprising that there was indeed an increase in cytotoxicity. The reasons for this are not clear but could be due to the effect of cytidine on two enzymes: cytidine deaminase (CDA) and ribonucleotide reductase (RNR).

Cytidine deaminase converts cytidine into uridine (which is also a mechanism of inactivating gemcitabine); RNR converts ribonucleotides to deoxyribonucleotides and is finely cross-regulated by each of its products (Thelander and Reichard, 1979). Uridine diphosphate (UDP) (from uridine) gets converted into deoxythymidine triphosphate (dTTP), which inhibits the conversion of CDP to dCDP by RNR (Thelander and Reichard, 1979). While it has been suggested that the dTTP-induced imbalance in dCTP pools is responsible for inhibition of DNA synthesis (Bjursell et al, 1973; Reichard, 1978; and Skoog et al, 1973), some investigators proposed that the decrease in the intracellular dCTP pool is too small to induce growth inhibition and that high levels of dTTP interact with regulators of DNA polymerase instead (Steinberg et al, 1979). Another interpretation is that the imbalance in pyrimidine pools leads to misincorporation of bases during DNA synthesis, leading to mutagenicity and cytotoxicity (Bradley and Sharkey, 1978). In either case, the cytotoxic effect of excess thymidine on tumor cells (melanoma and colon carcinoma) has been well established by Lee et al (1977). Tumor cells treated with 
thymidine for 72 hours showed less than $23 \%$ survival compared to the untreated control. In addition, it is possible that excess cytidine leads to CDA saturation, with a consequent decrease in gemcitabine deamination and increased bioavailability.

The increase in gemcitabine cytotoxicity in cells pre-treated with cytidine contradicts my earlier data suggesting that cytidine treatment is not cytotoxic. The reason for this inconsistency could be due to the technical difference of the assays used. FACS analyses were done immediately following cytidine treatment while MTT assays were performed following two days of gemcitabine treatment. The longer duration of gemcitabine exposure allows for at least one replication cycle, which requires a well-balanced nucleoside pool. Therefore, the effect of an imbalanced nucleoside pool was not reflected in cell viability right after cytidine treatment but may have been apparent after two days. This is supported by a previous report that compared colony formation, MTT and flow cytometry based cell viability assays and showed that the sensitivity of flow cytometry based cell viability assays increases considerably when viability assessment is deferred for up to 48 hours (Ross et al, 1989).

\section{Conclusion}

Taken together, I have shown a previously un-reported regulatory mechanism for hENT1. While substrate exposure does trigger hENT1 internalization, based on my findings, it does not appear to have a negative effect on gemcitabine efficacy. The data suggest that hENT1 is internalized when exposed to nucleoside concentrations higher than those found under normal physiological conditions (such as during nucleoside analog drug therapy) and that there are two populations of ENT1 at the membrane (active and inactive). These data fill in the gap in our knowledge with regards to the effect of nucleoside translocation on hENT1 function and presence at the PM. Because the overall nucleoside uptake remained unchanged, substrate 
dependent redistribution of hENT1 cannot have a negative impact on nucleoside analog drug efficacy. In terms of improving nucleoside analog drug efficacy, pre-treatment with cytidine seems to increase the efficacy of gemcitabine. My data show that pre-treatment with cytidine can be used to achieve a greater cytotoxic effect from a smaller dose of gemcitabine. The intracellular events responsible for the redistribution of hENT1 observed in this study remain to be investigated and some immediate next steps/experimental approaches are discussed below.

\section{Future directions}

Binding parameters of the two hNT1 populations

As mentioned earlier, the existence of two types of NBTI binding sites in HEK cells needs to be investigated further. The binding parameters $\left(\mathrm{K}_{d}\right.$ and $\left.\mathrm{B}_{\max }\right)$ need to be established with the use of a wider range of $\left[{ }^{3} \mathrm{H}\right] \mathrm{NBTI}$ concentrations, such as those used by Boumah et al (1992).

hENT1 degradation after internalization

As discussed, hENT1 likely undergoes degradation after internalization. There are two known mechanisms of protein degradation: lysosomal and ubiquitination/proteosomal degradation. To investigate whether hENT1 undergoes lysosomal or proteosomal degradation, marker antibodies for proteosomes and lysosomal stains can be used, followed by microscopy. Increased co-localization of HA-hENT1 with either lysosomes or proteosomes in cytidine treated cells compared to untreated cells would confirm protein degradation. 
Although Nivillac et al (2011) have already shown that hENT1 recycling occurs in a clathrin-dependent manner, the AP-2 (clathrin adaptor) recognition site needs to be confirmed. This can be done by site-directed mutagenesis of the putative AP-2 recognition sequence in the intracellular loop between TM domains 6 and 7, YQQL. Such a mutant could be generated using the HA-hENT1 construct designed for this thesis, which could then be used to perform FACS analyses identical to the ones described here. An increase in surface fluorescence from anti-HA antibody in AP-2 mutants treated with cytidine compared to wild type hENT1 treated with cytidine would confirm that YQQL site is the recognition sequence for AP-2. This is because AP-2 mutants would hinder routine and substrate dependent hENT1 recycling, resulting in no hENT1 internalization and therefore, an increase in PM hENT1 compared to wild type hENT1.

\section{Effect of cytidine pre-treatment on gemcitabine cytotoxicity}

I have confirmed that pretreatment with cytidine leads to an increase in gemcitabine cytotoxicity in the BxPC3 cell line. Next, we need to investigate whether shorter cytidine treatments (less than 6 hours) would also produce the same effect. This is because shorter pretreatments may be more convenient in the clinical setting. To translate our findings into a viable therapeutic regime, the effect of cytidine pretreatment needs to be confirmed in animal models. 


\section{Appendix}

A)

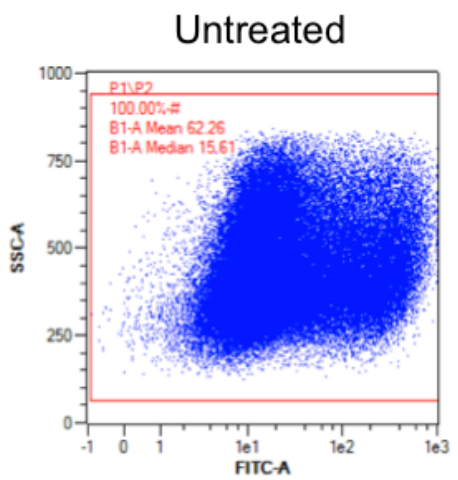

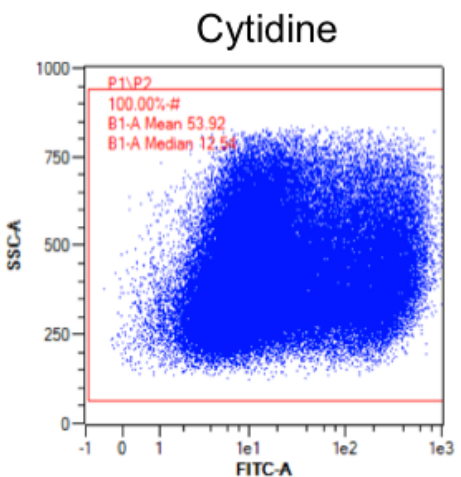

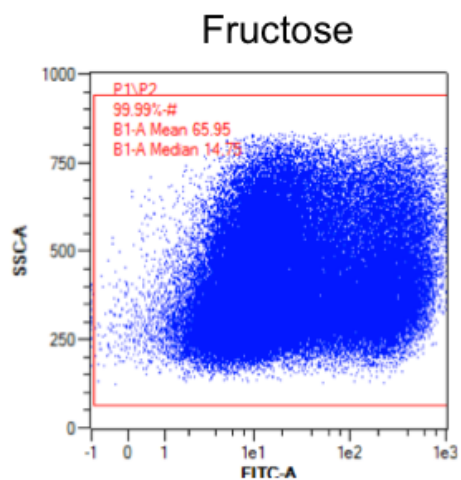

B)

\begin{tabular}{|c|c|}
\hline Condition & Mean Fluorescence \\
\hline untreated & 62.26 \\
\hline 40uM cytidine & 53.92 \\
\hline 400uM fructose & 65.95 \\
\hline
\end{tabular}

Figure 22: A) Dot-plot (FACS raw data) of HEK-293 cells treated with cytidine or fructose $(40 \mu \mathrm{M}, 6$ hours) 24 hours post-transfection with HA-hENT1. Following treatment, Alexa488 conjugated anti-HA antibody was used to label surface HA-hENT1 and cells were fixed with 4\% PFA. Quantification of fluorescence (B) shows a decrease in HA-hENT1 surface fluorescence after cytidine treatment, but not fructose treatment, when compared to untreated. Figure shows raw data from a representative experiment. Experiment was repeated three times and pooled, normalized data are shown in Figure 12. 


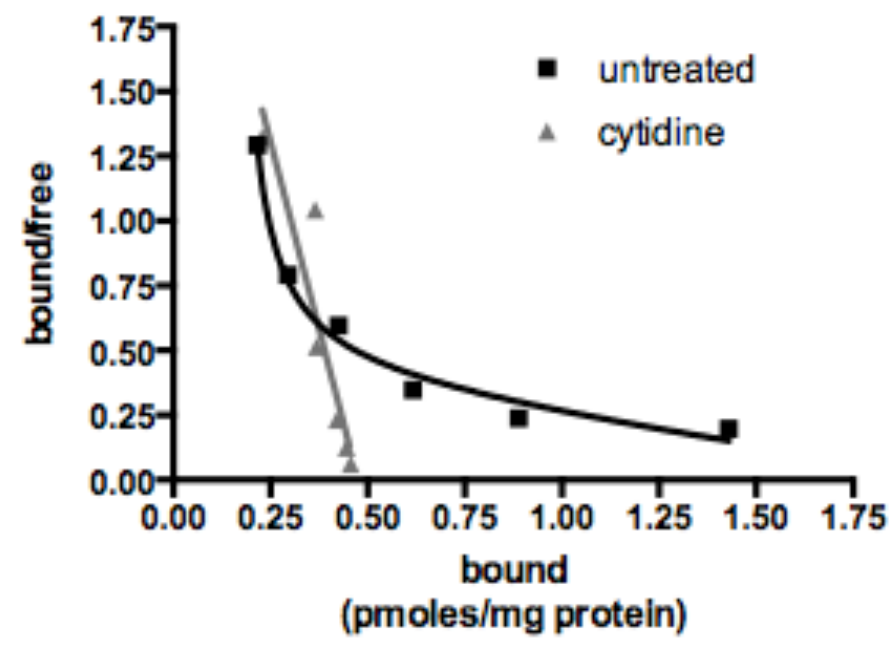

Figure 23: Combined Scatchard plot for the cytidine and untreated conditions shown in Figure16 B\&C. 


\section{Bibliography}

Abdulla, P. \& Coe, I.R., 2007. Characterization and functional analysis of the promoter for the human equilibrative nucleoside transporter gene, hENT1. Nucleosides, Nucleotides and Nucleic Acids 26(1),99-110.

Amanchy R, Periaswamy B, Mathivanan S, Reddy R, Tattikota SG, Pandey A. (2007). A curated compendium of phosphorylation motifs. Nat Biotechnol 25, 285-6.

Baldwin, S. et al. 2004. The equilibrative nucleoside transporter family, SLC29.Pflugers Archiv European Journal of Physiology 447, 735-743.

Bjursell, G., and Reichard, P. 1973. Effects of thymidine on deoxyribonucleoside triphosphate pools and deoxynbonucleic acid synthesis in Chinese hamster ovary cells. J. Biol. Chem. 248, 3904-3909.

Bone, D., Robillard, K., Stolk, M. \& Hammond, J. 2007. Differential regulation of mouse equilibrative nucleoside transporter 1 (mENT1) splice variants by protein kinase CK2.Mol Membr Biol 24, 294303.

Boumah, C.E., Hogue, D.L., Cass, C.E. 1992. Expression of high levels of nitrobenzylthioinosine-sensitive nucleoside transport in cultured human choriocarcinoma (BeWo) cells. Biochem J.15;288 ( Pt 3), 987-96.

Bradley, M. 0., and Sharkey, N. A. 1978. Mutagenicity of thymidine to cultured Chinese hamster cells. Nature (Lond.) 274, 607-608.

Calotti, P. et al. 2008. Modulation of the human equilibrative nucleoside transporter1 (hENT1) activity by IL-4 and PMA in B cells from chronic lymphocytic leukemia.Biochemical Pharmacology 75, 857-865 (2008).

Cavalcante, L. \& Monteiro, G. 2014. Gemcitabine: metabolism and molecular mechanisms of action, sensitivity and chemoresistance in pancreatic cancer. Eur. J. Pharmacol. 741, 8-16.

Cerecedo, L.R., 1927. Studies on the Physiology of Pyrimidines. The Journal of biological chemistry. 75, 661-670.

Chaudary, N., Naydenova, Z., Shuralyova, I. \& Coe, I. 2004 Hypoxia regulates the adenosine transporter, mENT1, in the murine cardiomyocyte cell line, HL-1. Cardiovasc. Res. 61, 780-8.

Chaudary, N., Shuralyova, I., Liron, T., Sweeney, G. \& Coe, I. 2002. Transport characteristics of HL-1 cells: a new model for the study of adenosine physiology in cardiomyocytes. Biochem. Cell Biol. 80, 655-665. 
Choi, D.S., Handa, M., Young, H., Gordon, A.S., Diamond, I., Messing, R.O. 2000. Genomic organization and expression of the mouse equilibrative, nitrobenzylthioinosine-sensitive nucleoside transporter 1 (ENT1) gene. Biochem Biophys Res Commun. 277(1), 200-8.

Chuang, J.Z., Vega, C., Jun, W., Sung, C.H. 2004. Structural and functional impairment of endocytic pathways by retinitis pigmentosa mutant rhodopsin-arrestin complexes. J Clin Invest. 114(1), 131-40.

Coe, I., Zhang, Y., McKenzie, T. \& Naydenova, Z. 2002. PKC regulation of the human equilibrative nucleoside transporter, hENT1. FEBS Letters 517, 201-205.

Conner, S.D., Schmid, S.L. 2003. Regulated portals of entry into the cell. Nature. 422,37-44.

Doherty, G.J., McMahon, H.T. 2009.Mechanisms of Endocytosis. Annu Rev Biochem. 78,857902.

Endres, C.J. \& Unadkat, J.D., 2005. Residues Met89 and Ser160 in the human equilibrative nucleoside transporter 1 affect its affinity for adenosine, guanosine, S6-(4-nitrobenzyl)mercaptopurine riboside, and dipyridamole. Molecular pharmacology. 67(3), pp.837-844.

Fernández Calotti P, Galmarini CM, Cañones C, Gamberale R, Saénz D, Avalos JS, Chianelli M, Rosenstein R, Giordano M. 2008. Modulation of the human equilibrative nucleoside transporter1 (hENT1) activity by IL-4 and PMA in B cells from chronic lymphocytic leukemia. Biochem Pharmacol 75,857-865.

Gandhi, V., Legha, J., Chen, F., Hertel, L.W., Plunkett, W. 1996. Excision of 2',2'difluorodeoxycytidine (gemcitabine) monophosphate residues from DNA. Cancer Res. 56(19),4453-9.

Gati WP, Paterson ARP, Larratt LM, Turner AR and Belch AR. 1997. Sensitivity of acute leukemia cells to cytarabine is a correlate of cellular es nucleoside transporter site content measured by flow cytometry with SAENTA-fluorescein. Blood. 90 (1), 346-353.

Geiger, J.D., LaBella, F.S. \& Nagy, J.I., 1985. Characterization of nitrobenzylthioinosine binding to nucleoside transport sites selective for adenosine in rat brain. The Journal of neuroscience : the official journal of the Society for Neuroscience. 5 (3), 735-740.

Gemzar, 2013. Drug label. Lilly, USA. Reference ID: 3503046

Giovannetti, E. et al. 2006. Transcription analysis of human equilibrative nucleoside transporter1 predicts survival in pancreas cancer patients treated with gemcitabine.Cancer Res. 66, 392835 .

Grant, B. \& Donaldson, J. 2009. Pathways and mechanisms of endocytic recycling. Nat. Rev. Mol. Cell Biol. 10, 597-608. 
Harding C, Heuser J, Stahl P. 1983. Receptor-mediated endocytosis of transferrin and recycling of the transferrin receptor in rat reticulocytes. J Cell Biol. 97(2),329-39.

Hou, J., Williams, D., Vicogne, J. \& Pessin, J. 2009. The glucose transporter 2 undergoes plasma membrane endocytosis and lysosomal degradation in a secretagogue-sependent manner.Endocrinology 150, 4056-4064.

Huang, P., Chubb, S., Hertel, L.W., Grindey, G.B., Plunkett, W., 1991. Action of 2',2'difluorodeoxycytidine on DNA synthesis. Cancer Res. 51,6110-6117.

Hughes, S., Cravetchi, X., Vilas, G. \& Hammond, J. 2015. Adenosine A1 receptor activation modulates human equilibrative nucleoside transporter 1 (hENT1) activity via PKC-mediated phosphorylation of serine-281. Cellular Signalling 27,1008-1018.

Jarvis SM, Ellory JC, Young JD.1986. Radiation inactivation of the human erythrocyte nucleoside and glucose transporters. Biochim Biophys Acta. 855(2), 312-5.

Johnson, Z., Cheong, C.-G. \& Lee, S.-Y. 2012. Crystal structure of a concentrative nucleoside transporter from Vibrio cholerae at $2.4 \AA$. Nature 483, 489-493.

Jordheim, L., Durantel, D., Zoulim, F. \& Dumontet, C. 2013. Advances in the development of nucleoside and nucleotide analogues for cancer and viral diseases. Nat Rev Drug Discov 12,447464.

Kalckar, H.M. 1950. The biological incorporation of purines and pyrimidines into nucleosides and nucleic acid. Biochimica et biophysica acta. 4(1-3), 232- 237.

Katagiri, H. et al. 1992. Replacement of intracellular C-terminal domain of GLUT1 glucose transporter with that of GLUT2 increases Vmax and Km of transport activity. $J$ Biol Chem. 267(31),22550-5.

Kibbey, R., Rizo, J., Gierasch, L. \& Anderson, R. 1998. The LDL Receptor Clustering Motif Interacts with the Clathrin Terminal Domain in a Reverse Turn Conformation. The Journal of Cell Biology 142, 59-67.

King, A.E. et al., 2006. Nucleoside transporters: from scavengers to novel therapeutic targets. Trends in pharmacological sciences. 27(8), 416-425.

Lee, S. S., Giovanotta, B. C., and Stehlin, J. S., Jr. 1977. Selective lethal effect of thymidine on human and mouse tumor cells. J. Cell. Phystol., 92, 401-405.

Mackey JR, Mani RS, Seiner M, Mowles D, Young JD, Belt JA, Crawford CR, and Cass CE. 1998. Functional nucleoside transporters are required for gemcitabine influx and manifestation of toxicity in cancer cell lines. Cancer Res. 58, 4349-4357. 
Morote-Garcia, J., Rosenberger, P., Nivillac, N., Coe, I. \& Eltzschig, H. 2009. HypoxiaInducible Factor-Dependent Repression of Equilibrative Nucleoside Transporter 2 Attenuates Mucosal Inflammation During Intestinal Hypoxia.Gastroenterology 136, 607-618.

Muñoz G, San Martín R, Farías M, Cea L, Vecchiola A, Casanello P, Sobrevia L. 2006. Insulin restores glucose inhibition of adenosine transport by increasing the expression and activity of the equilibrative nucleoside transporter 2 in human umbilical vein endothelium. J Cell Physiol. 209(3),826-35.

Newton AC. 2003. Regulation of the ABC kinases by phosphorylation, protein kinase $\mathrm{C}$ as a paradigm. Biochem J. 370, 361-71.

Nivillac, N., Bacani, J. \& Coe, I. 2011. The life cycle of human equilibrative nucleoside transporter 1: From ER export to degradation. Experimental Cell Research 317, 1567-1579.

Panigrahi, R. et al. 2014. Persistent Hepatitis C Virus Infection Impairs Ribavirin Antiviral Activity through Clathrin-Mediated Trafficking of Equilibrative Nucleoside Transporter 1. J. Virol. 89,626-642.

Park, J. \& Hammond, J. 2012. Cysteine Residues in the Transmembrane (TM) 9 to TM11 Region of the Human Equilibrative Nucleoside Transporter Subtype 1 Play an Important Role in Inhibitor Binding and Translocation Function. Molecular Pharmacology82, 784-794.

Pastor-Anglada, M., Felipe, A. \& Casado, F.J., 1998. Transport and mode of action of nucleoside derivatives used in chemical and antiviral therapies. Trends in pharmacological sciences. 19(10), 424-430.

Pennycooke, M., Chaudary, N., Shuralyova, I., Zhang, Y. \& Coe, I. 2001. Differential Expression of Human Nucleoside Transporters in Normal and Tumor Tissue. Biochemical and Biophysical Research Communications 280, 951-959.

Piomboni, P., Focarelli, R., Stendardi, A., Ferramosca, A. \& Zara, V. 2012. The role of mitochondria in energy production for human sperm motility. Int. J. Androl. 35, 109-124.

Procino G, Carmosino M, Marin O, Brunati AM, Contri A, Pinna LA, Mannucci R, Nielsen S, Kwon TH, Svelto M, Valenti G. 2003. Ser-256 phosphorylation dynamics of Aquaporin 2 during maturation from the ER to the vesicular compartment in renal cells. FASEB J. 17,1886-8.

Puebla, C. et al., 2008. High D-glucose reduces SLC29A1 promoter activity and adenosine transport involving specific_protein 1 in human umbilical vein endothelium. Journal of Cellular Physiology. 215(3), 645-656.

Racine V, Sachse M, Salamero J, Fraisier V, Trubuil A, Sibarita JB. (2007). Visualization and quantification of vesicle trafficking on a three-dimensional cytoskeleton network in living cells. J Microsc. 225, 214-28.

Reichard, P. 1978. From deoxynucteotides to DNA synthesis. Fed. Proc. 37, 9-14. 
Reyes, G. et al. 2011. The Equilibrative Nucleoside Transporter (ENT1) can be phosphorylated at multiple sites by PKC and PKA. Mol Membr Biol 28, 412-426.

Robillard, K., Bone, D., Park, J. \& Hammond, J. 2008. Characterization of mENT1 $\Delta 11$, a Novel Alternative Splice Variant of the Mouse Equilibrative Nucleoside Transporter 1. Mol. Pharmacol.74, 264-273.

Rose, J. \& Coe, I. 2008. Physiology of Nucleoside Transporters: Back to the Future. . . . Physiology 23,41-48.

Rose, J. et al. 2010. Equilibrative nucleoside transporter 1 plays an essential role in cardioprotection. Am. J. Physiol. Heart Circ. Physiol. 298, H771-H777.

Rose, J. et al. 2011. Absence of equilibrative nucleoside transporter 1 in ENT1 knockout mice leads to altered nucleoside levels following hypoxic challenge. Life Sciences 89,621-630.

Rosenthal, H.E. 1967. A graphic method for the determination and presentation of binding parameters in a complex system. Anal Biochem. 20(3), 525-32.

Ross, D.D., Joneckis, C.C., Ordóñez, J.V., Sisk, A.M., Wu, R.K., Hamburger, A.W. Nora, R.E., Nora, R.E. 1989. Estimation of cell survival by flow cytometric quantification of fluorescein diacetate/propidium iodide viable cell number. Cancer Res. 49(14), 3776-82.

Saunders, C. et al. 2000. Amphetamine-induced loss of human dopamine transporter activity: An internalization-dependent and cocaine-sensitive mechanism. Proceedings of the National Academy of Sciences 97, 6850-6855.

Sengupta, D.J. et al., 2002. A single glycine mutation in the equilibrative nucleoside transporter gene, hENT1, alters nucleoside transport activity and sensitivity to nitrobenzylthioinosine. Biochemistry. 41(5), 1512-1519.

Séron K, Blondel MO, Haguenauer-Tsapis R, and Volland C. 1999. Uracil-induced downregulation of the yeast uracil permease. J Bacteriol. 181(6), 1793-1800.

Skoog, K. L, NordenskjcW, B. A., and Bjursell. K. G. 1973. Deoxyribonudeoside- triphosphate pools and DNA synthesis in synchronized hamster cells. Eur. J. Biochem. 33, 428-432.

Spratlin J, Sangha R, Glubrecht D, Dabbagh L, Young JD, Dumontet C, Cass C, Lai R, Mackey JR. 2004. The absence of human equilibrative nucleoside transporter 1 is associated with reduced survival in patients with gemcitabine-treated pancreas adenocarcinoma. Clin Cancer Re.s 10, $6956-6961$.

Steinberg, J. A., Otten, M., and Grindey, G. B. 1979. Isolation of a DNA polymerase alphaassociated regulatory protein from calf thymus. Cancer Res. 39, 4330-4335. 
Tan, M.H. et al. 1986. Characterization of a new primary human pancreatic tumor line. Cancer Invest. 4(1), 15-23.

Thelander, L., Reichard, P. 1979. Reduction of ribonucleotides. Annu Rev Biochem. 48,133-58.

Torres M, Delicado EG, Fideu MD, Miras-Portugal MT. 1992. Down-regulation and recycling of the nitrobenzylthioinosine-sensitive nucleoside transporter in cultured chromaffin cells. Biochim Biophys Acta.1105(2), 291-9.

Ueno, H., Kiyosawa, K., Kaniwa, N.2007. Pharmacogenomics of gemcitabine: can genetic studies lead to tailor-made therapy? Br J Cancer. 97(2), 145-51.

Valdes, R., Elferich, J., Shinde, U. \& Landfear, S. 2014. Identification of the Intracellular Gate for a Member of the Equilibrative Nucleoside Transporter (ENT) Family. Journal of Biological Chemistry. 289, 8799-8809.

Valdés, R., Shinde, U. \& Landfear, S. 2012. Cysteine Cross-linking Defines the Extracellular Gate for the Leishmania donovani Nucleoside Transporter 1.1 (LdNT1.1). J. Biol. Chem. 287, 44036-44045.

van Balkom, B.W.M. et al., 2002. The role of putative phosphorylation sites in the targeting and shuttling of the aquaporin-2 water channel. The Journal of biological chemistry, 277(44), 4147341479 .

Vickers, M.F. et al., 1999. Functional production and reconstitution of the human equilibrative nucleoside transporter (hENT1) in Saccharomyces cerevisiae. Interaction of inhibitors of nucleoside transport with recombinant hENT1 and a glycosylation-defective derivative (hENT1/N48Q). The Biochemical journal, 339 ( Pt 1)21-32.

Wei, M., Kuukasjärvi, P., Laurikka, J., Honkonen, E.L., Kaukinen, S., Laine, S., Tarkka, M. 2001. Cardioprotective effect of adenosine pretreatment in coronary artery bypass grafting. Chest. 120(3), 860-5.

Yao, S., Ng, A., Cass, C., Baldwin, S. \& Young, J. 2011. Nucleobase Transport by Human Equilibrative Nucleoside Transporter 1 (hENT1). J. Biol. Chem. 286,32552-32562.

Young, J., Yao, S., Baldwin, J., Cass, C. \& Baldwin, S. 2013. The human concentrative and equilibrative nucleoside transporter families, SLC28 and SLC29. Molecular Aspects of Medicine34, 529547.

Young, J., Yao, S., Sun, L., Cass, C. \& Baldwin, S. 2008. Human equilibrative nucleoside transporter (ENT) family of nucleoside and nucleobase transporter proteins. Xenobiotica. 38(78), 995-1021. 
Zhang, Q. et al. 2008. Organic Anion Transporter OAT1 Undergoes Constitutive and Protein Kinase C-regulated Trafficking through a Dynamin- and Clathrin-dependent Pathway. Journal of Biological Chemistry 283, 32570-32579. 